\title{
Revision of the worm eel genus Neenchelys (Ophichthidae: Myrophinae), with descriptions of three new species from the western Pacific Ocean
}

\author{
Hsuan-Ching Ho ${ }^{1 *}$, John E McCosker ${ }^{2}$ and David G Smith ${ }^{3}$
}

\begin{abstract}
Background: The Indo-Pacific snake eel genus Neenchelys is a small group of moderately to extremely elongated fishes (family Ophichthidae), which comprises seven nominal species previously. Intensive collections on this group have led to the findings of taxonomic problems, as well as new taxa. This study is aimed to review the group on the basis of all known specimens, to verify the species, and to describe the new species.

Results: Six valid species are recognized: Neenchelys microtretus Bamber from the Suez, Red Sea; N. buitendijki Weber and de Beaufort from Indonesia, Bombay, India, and Malaysia; N. cheni (Chen and Weng), a senior synonym of N. retropinna Smith and Böhlke, from Taiwan, Vietnam, Australia, and the Gulf of Oman; N. daedalus McCosker from Papua New Guinea; N. parvipectoralis Chu, Wu and Jin from the South China Sea off Taiwan and Vietnam; and N. mccoskeri Hibino, Ho and Kimura from Japan and Taiwan. Three new species - N. diaphora sp. nov., N. pelagica sp. nov., and N. similis sp. nov. - are described from Taiwan and Japan. These new species differ from the congeners in body proportions, meristics, and morphology. A lectotype for N. buitendijki is designated.

Conclusions: Totally, nine species are recognized in Neenchelys, including three new species, with most species showing range extension in the Indo-west Pacific region. Diagnosis, detailed morphometric and meristic data, and ecological note for each species are provided. New diagnostic characters are used for recognizing the species, with a key to the species of Neenchelys provided. The recent discovery of new Asian species suggests that more remain to be discovered.
\end{abstract}

Keywords: Pisces; Anguilliformes; Ophichthidae; Myrophinae; Neenchelys; Taiwan

\section{Background}

The ophichthid eel genus Neenchelys Bamber 1915 is a group of small elongate ophichthid eels, subfamily Myrophinae, characterized by a posterior nostril opening on the side of the head above the lip and by having one or two preopercular pores and a pectoral fin. Species of Neenchelys inhabit the western Pacific and Indian oceans, and some, like species of Benthenchelys Fowler 1934 (see Castle 1972), are unique among ophichthids, nearly all of which are benthic burrowers as juveniles and adults, in inhabiting the midwater realm throughout their lives.

\footnotetext{
* Correspondence: ogcoho@gmail.com

'National Museum of Marine Biology and Aquarium and Institute of Marine Biodiversity and Evolutionary Biology, National Dong Hwa University, Pingtung 944, Taiwan

Full list of author information is available at the end of the article
}

Since the genus was established, only few species were described under it: Neenchelys buitendijki Weber and de Beaufort 1916 from Indonesia, Neenchelys parvipectoralis Chu, Wu and Jin 1981 from China, Neenchelys daedalus McCosker 1982 from Papua New Guinea, Neenchelys retropinna Smith and Böhlke 1983 from Gulf of Oman, and Neenchelys mccoskeri Hibino, Ho and Kimura 2012 from northwestern Pacific Ocean.

Although McCosker (1982) separated Neenchelys from the closely related New World genus Pseudomyrophis Wade 1946 by its having well-developed pectoral fins and lacking the third preopercular pore, some members of Neenchelys in the Indo-western Pacific possess a minute pectoral fin. All species of Neenchelys have two rather than three preopercular pores (except for $N$. parvipectoralis which usually has one), a significant character among many species of ophichthids (McCosker 1977). 
McCosker and Chen (2000) recorded N. retropinna from Taiwan. Mohamed (1958) and Ho et al. (2012) recorded $N$. buitendijki from Bombay, India, the Arabian Sea, and Malaysia. Ho et al. (2010) discovered the missing type series of Myrophis cheni Chen and Weng 1967 and suggested that it might be a member of Neenchelys and that $N$. retropinna was its junior synonym. We concur. Ho et al. (2010) also reported on six specimens of $N$. parvipectoralis from waters off Taiwan. Machida and Ohta (1993) recorded a specimen of $N$. daedalus from Japan, and Chen (2007) recognized an additional specimen from Taiwan. Both specimens belong to a new species described herein.

In recent investigations, we discovered three undescribed species of Neenchelys from the waters of southern Taiwan, one of which is presumably a midwater species and the others are presumably demersal species. The addition of three new species described herein brings the total number of species in Neenchelys to nine.

It is the purpose of this paper to describe and name the three new species, review all Indo-Pacific species of Neenchelys, and provide a key to their identification.

\section{Methods}

Measurements are straight line, made either with a $300-\mathrm{mm}$ ruler with $0.5-\mathrm{mm}$ gradations (for total length (TL), trunk length, and tail length) and recorded to the nearest $0.5 \mathrm{~mm}$, or with dial calipers (all other measurements) and recorded to the nearest $0.1 \mathrm{~mm}$. Body length comprises the head (HL) and trunk lengths. The HL was measured from the snout tip to the posterodorsal margin of the gill opening, the trunk length was taken from the end of the head to the mid-anus, and the maximum body depth did not include the median fins. The head pore terminology followed that of McCosker et al. (1989: 257) in that the supraorbital pores are expressed as the ethmoidal pore + pores in the supraorbital canal, e.g., $1+4$, and the infraorbital pores are expressed as pores along the upper jaw + those in the vertical part of the canal behind the eye ('postorbital pores'), e.g., $4+2$, in that the last pore included along the upper jaw is frequently part of the postorbital series.

Vertebral counts (which include the hypural) were taken from radiographs. The mean vertebral formula (MVF) is expressed as the average of the predorsal, preanal, and total vertebrae (Böhlke 1989). All specimens examined in this study were preserved in formaldehyde and then transferred to ethyl alcohol or isopropyl alcohol. Specimens examined in this study are deposited at the Australian Museum, Sydney, Australia (AMS); Academy of Natural Sciences, Philadelphia, PA, USA (ANSP); Institute of Zoology, Chinese Academy of Sciences, Beijing, China (ASIZB); Biodiversity Research Center, Academia Sinica, Taipei, Taiwan (ASIZP); Natural History Museum, London,
UK (BMNH); Fisheries Research Laboratory, Mie University, Mie, Japan (FRLM); California Academy of Sciences, California, USA (CAS); National Science Museum, Tokyo, Japan (NSMT-P); Pisces Collection, National Museum of Marine Biology \& Aquarium (NMMB-P); Shanghai Ocean University, Shanghai, China (formerly Shanghai Fishery College; SFC); Laboratory of Aquatic Ecology, Department of Aquaculture, National Taiwan Ocean University (TOU-AE); Smithsonian Institution, National Museum of Natural History, Washington D. C., USA (USNM); and Zoölogisch Museum, Amsterdam, The Netherlands (ZMA). Institutional abbreviations follow Fricke and Eschmeyer (2013, online version).

\section{Systematics}

\section{Neenchelys Bamber 1915}

Synonymy: Neenchelys Bamber 1915: 479 (type species: Neenchelys microtretus Bamber 1915, by monotypy); Mohamed 1958: 511; McCosker 1977: 60; McCosker 1982: 62; McCosker et al. 1989: 270; Smith and McCosker 1999: 1663.

Diagnosis: Ophichthid eels, subfamily Myrophinae, tribe Myrophini (sensu McCosker 1977) with the following characteristics: body robust to extremely elongate, cylindrical anteriorly, and somewhat laterally compressed posteriorly; head and trunk shorter than tail; dorsal fin origin variable, from anterior trunk region to slightly behind level of anus; pectoral fin variable in size, from minute to moderately developed; snout broad, tumid, overhanging lower jaw; lips without barbels; anterior nostril tubular, posterior nostril an elongate slit in upper lip beneath lower margin of orbit; gill opening round and constricted; cephalic pores developed, one or two preopercular pores (usually two, except for $N$. parvipectoralis); teeth small, conical, mostly uniserial on jaws and vomer; coloration uniform although slightly darker dorsally, median fins often black-edged posteriorly.

Distribution and ecological notes: Members of Neenchelys can be found in the Indo-west Pacific region from the Red Sea east to Papua New Guinea, north to Japan, and south to western Australia. As stated above, some species of Neenchelys are remarkable in that they are known or suspected to live in midwater as adults. All but three (Benthenchelys spp.) of the more than 260 other known species of ophichthids (McCosker 2014) are fossorial and burrow in sand, gravel, or muddy substrates.

Remarks: On the basis of a $185-\mathrm{mm}$ specimen, Bamber (1915) created the family Neenchelidae and a new genus and species. The family was subsequently included within the Ophichthidae (Böhlke 1960; Nelson 1966, 1967). Species of Neenchelys are most closely related to those of the New World genus Pseudomyrophis. Previous researchers (including Gareth J. Nelson and the late James E. Böhlke) suggested that the two genera might be synonymous; 
however, based on trenchant differences displayed by the leptocephali, Leiby (1984) strongly advised that the genera are valid. We concur with this.

There are now nine known species; however, the recent discovery of four new Asian species suggests that more remain to be discovered.

Etymology: From the Greek neo (new) and enchelys (eel). Treated as feminine according to Opinion 915 of the Bulletin of Zoological Nomenclature (1970).

\section{Neenchelys buitendijki Weber and de Beaufort 1916}

Common name: Fintail serpent eel

(Figure 1 A,B,C,D and Tables 1 and 2)

Synonymy: Neenchelys buitendijki Weber and de Beaufort 1916: 268, Figure one hundred sixteen (type localities: Bay of Batavia, Java, and probably Moluccas, Indonesia); Mohamed 1958: 513; Ho et al. 2012: 949.

Material examined: Syntype (herein designated to be the lectotype): ZMA.102.171 (218 mm TL), 'Moluccas,

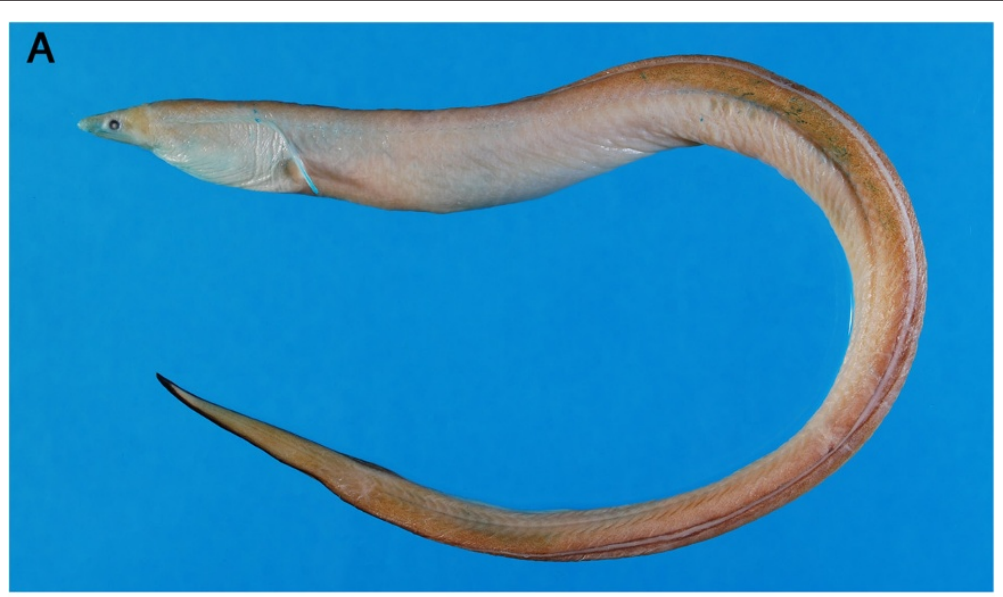

B
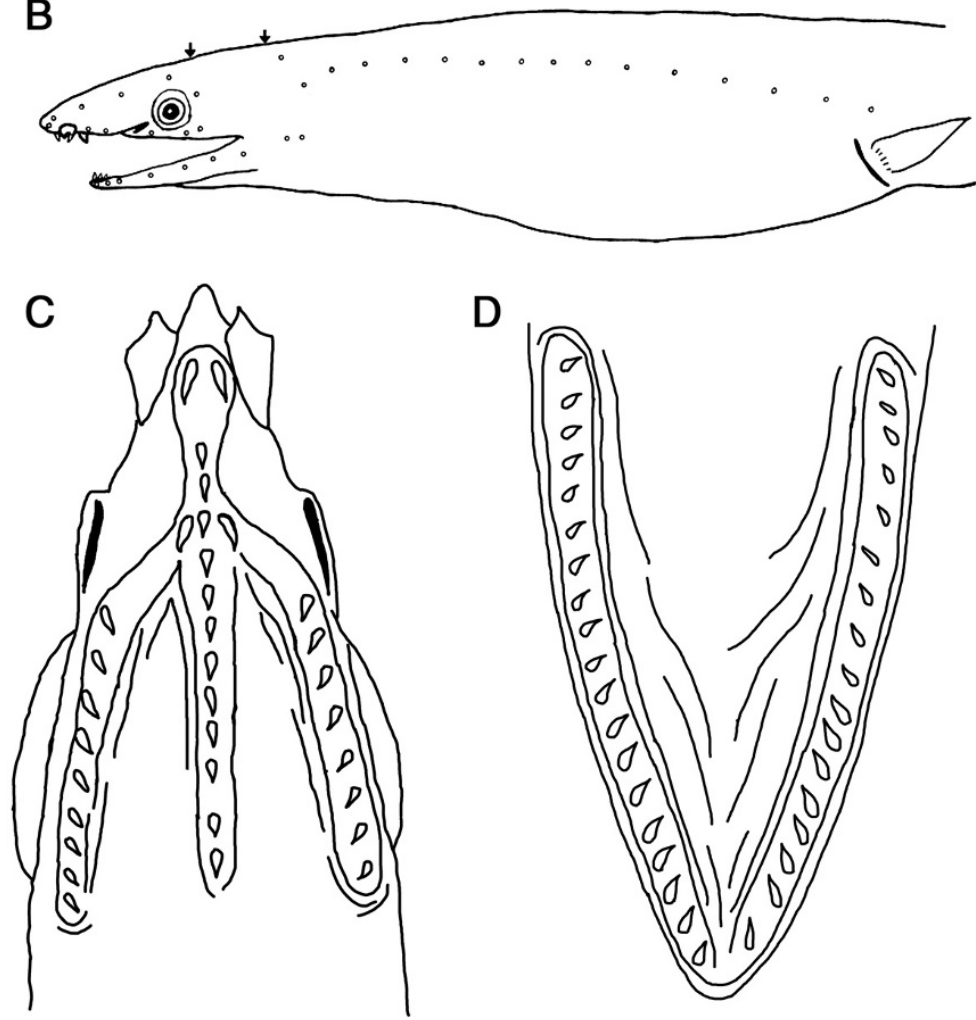

D

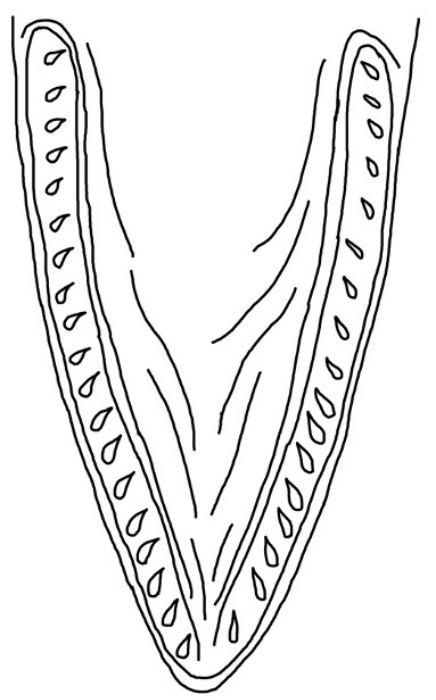

Figure 1 Neenchelys buitendijki Weber and de Beaufort 1916. (A) NMMB-P13649, 239 mm TL, Matang, Malaysia, preserved condition. (B) Lateral view of head, with arrows indicating the frontal pore (left) and median supratemporal pore (right). (C) Upper jaw teeth. (D) Lower jaw teeth. (B-D) From NMMB-P13651, $211 \mathrm{~mm}$ TL 
Table 1 Morphometric data of five Neenchelys species, expressed as percentage of total length, trunk length, and head length

\begin{tabular}{|c|c|c|c|c|c|c|c|c|c|c|}
\hline & \multirow{2}{*}{\multicolumn{2}{|c|}{$\begin{array}{c}\text { N. buitendijki } \\
n=7\end{array}$}} & \multicolumn{3}{|c|}{ N. cheni } & \multirow{2}{*}{$\frac{\text { N. daedalus }}{n=2}$} & \multicolumn{2}{|c|}{ N. diaphora sp. nov. } & \multirow{2}{*}{\multicolumn{2}{|c|}{$\begin{array}{l}\text { N. mccoskeri } \\
n=31\end{array}$}} \\
\hline & & & Lectotype & $n=17$ & & & Holotype & Types $(n=3)$ & & \\
\hline Total length $(\mathrm{mm})$ & $170-239$ & & 334 & $334-414$ & & $273-342$ & 478 & $264-478$ & $283-522$ & \\
\hline$\%$ Total length & Mean (range) & SD & & Mean (range) & SD & & & Mean (range) & Mean (range) & SL \\
\hline Head length & $12.2(11.0-14.1)$ & 1 & 8.6 & $9.5(8.6-12.2)$ & 0.8 & $6.9-7.8$ & 10.1 & $9.8(9.3-10.1)$ & $7.1(6.4-7.7)$ & 0.3 \\
\hline Predorsal length & 17.3 (16.7-18.6) & 0.8 & 37.7 & $40.0(37.7-41.9)$ & 1.4 & $14.5-15.4$ & 22.6 & $22.4(21.9-22.8)$ & $23.0(21.1-25.6)$ & 1 \\
\hline Trunk length & $29.3(26.8-32.4)$ & 1.7 & 27.2 & $28.6(26.9-31.1)$ & 1 & 19.0-19.6 & 25.3 & $25.1(23.8-26.3)$ & 33.1 (30.9-36.6) & 1.3 \\
\hline Preanal length & $42.7(41.0-46.5)$ & 2.3 & 36.2 & $38.1(36.2-39.8)$ & 1.1 & $25.9-27.4$ & 35.6 & $35.0(33.7-35.6)$ & $40.1(34.6-43.7)$ & 1.7 \\
\hline Tail length & $59.7(55.2-61.8)$ & 2.2 & 64.4 & $61.8(60.2-64.4)$ & 1.1 & $72.6-74.1$ & 64.9 & $65.2(64.4-66.3)$ & $59.6(56.5-62.8)$ & 1.5 \\
\hline \multicolumn{11}{|l|}{$\%$ Trunk length } \\
\hline $\begin{array}{l}\text { Gill opening to } \\
\text { dorsal fin origin }\end{array}$ & $18.1(16.6-19.2)$ & 1.1 & 106.9 & $107.3(97.4-116.8)$ & 4.1 & $38.5-40.0$ & 49.2 & $50.2(49.2-51.3)$ & $48.1(43.6-53.4)$ & 2.5 \\
\hline \multicolumn{11}{|l|}{$\%$ Head length } \\
\hline Pectoral fin length & $21.8(15.0-25.5)$ & 3.5 & 13.2 & $13.3(10.3-16.4)$ & 1.5 & $22.1-23.4$ & 26.8 & $26.2(25.0-26.8)$ & $2.6(1.5-3.5)$ & 0.6 \\
\hline Snout length & 15.6 (13.6-17.6) & 1.3 & 22.6 & $21.7(19.1-24.2)$ & 1.3 & $16.6-17.8$ & 19.4 & $19.2(19.0-19.4)$ & $19.7(15.8-23.1)$ & 1.8 \\
\hline Eye diameter & $4.8(4.4-5.3)$ & 0.3 & 7.3 & $7.9(6.2-10.2)$ & 1.1 & $5.1-5.6$ & 6.6 & $6.5(6.1-6.8)$ & $6.4(4.0-8.4)$ & 0.9 \\
\hline Upper jaw length & $28.3(26.5-32.4)$ & 2 & 30 & $32.2(26.6-37.1)$ & 2.7 & $24.3-26.4$ & 29.3 & $30.4(29.3-31.3)$ & $30.7(27.9-37.2)$ & 2 \\
\hline Interorbital width & $7.5(7.1-8.5)$ & 0.5 & 12.5 & $13.4(10.8-15.6)$ & 1.4 & $8.4-8.7$ & 13.6 & $13.8(13.3-14.6)$ & $12.6(10.4-16.1)$ & 1.5 \\
\hline Postorbital length & $78.5(72.4-83.4)$ & 4.1 & 75.6 & $73.6(69.5-75.6)$ & 1.8 & - & 72.2 & $75.4(72.2-79.0)$ & $75.3(70.2-82.5)$ & 3 \\
\hline Gill opening height & $12.9(11.8-15.7)$ & 1.6 & 6.6 & $8.2(5.6-13.5)$ & 2.4 & - & 12.6 & $11.0(8.8-12.6)$ & $8.7(6.3-11.9)$ & 1.3 \\
\hline Depth at head & $22.8(17.6-36.2)$ & 6.6 & 30 & $31.5(27.2-37.3)$ & 3.3 & - & 35.7 & $32.3(30.3-35.7)$ & $32.4(25.0-42.0)$ & 4.2 \\
\hline Depth at anus & $34.9(30.9-38.5)$ & 2.8 & 24.4 & $26.1(19.4-30.1)$ & 3 & $27.6-27.7$ & 39.2 & $40.6(32.6-50.0)$ & $35.1(28.7-48.7)$ & 4.3 \\
\hline Width at anus & $25.7(20.7-30.5)$ & 4.1 & 17.1 & $19.4(16.1-23.5)$ & 2.2 & $16.4-17.9$ & 33.8 & $32.8(27.2-37.5)$ & $31.1(24.2-37.4)$ & 3.7 \\
\hline
\end{tabular}

Indonesia'. Non-types: Malaysia: NMMB-P13649 (239 mm), offshore, $04^{\circ} 49^{\prime} 30.42^{\prime \prime} \mathrm{N}, 100^{\circ} 29^{\prime} 11.76^{\prime \prime} \mathrm{E}$, Matang, small otter trawl, 6 October 2009; NMMB-P13650 (198 mm), mudflat, Matang, $04^{\circ} 51^{\prime} 1.26^{\prime \prime} \mathrm{N}, 100^{\circ} 31^{\prime} 10.8^{\prime \prime} \mathrm{E}$, small otter trawl, 3 m, 1 December 2009; NMMB-P13651 (211 mm), offshore, 04⒋ $54.18^{\prime \prime} \mathrm{N}, 100^{\circ} 29^{\prime} 37.38^{\prime \prime} \mathrm{E}$, Matang, small otter trawl, $3.3 \mathrm{~m}, 16$ January 2010; NMMB-P13652 (225 mm), mudflat, $04^{\circ} 50^{\prime} 53.64^{\prime \prime} \mathrm{N}, 100^{\circ} 30^{\prime} 49.32^{\prime \prime} \mathrm{E}$, Matang, small otter trawl, 1.9 m, 16 January 2010; NMMBP13653 (192 mm), mudflat, Matang, 04 50 '48.48"N, $100^{\circ}$

Table 2 Meristic data of five Neenchelys species treated in present study

\begin{tabular}{|c|c|c|c|c|c|c|c|}
\hline & \multirow{2}{*}{$\frac{\text { N. buitendijki }}{n=7}$} & \multicolumn{2}{|c|}{ N. cheni } & \multirow{2}{*}{$\frac{\text { N. daedalus }}{n=2}$} & \multicolumn{2}{|c|}{ N. diaphora sp. nov. } & \multirow{2}{*}{$\frac{\text { N. mccoskeri }}{n=36}$} \\
\hline & & Lectotype & $n=17$ & & Holotype & Types $(n=3)$ & \\
\hline Total vertebrae & $135-140$ & 181 & $180-183$ & $225-235$ & 186 & $177-186$ & $172-184$ \\
\hline Predorsal vertebrae & $18-20$ & 58 & $56-60$ & 31 & 34 & 34 or 35 & $34-41$ \\
\hline Preanal vertebrae & $49-51$ & 55 & $52-58$ & 58 or 59 & 54 & 54 or 55 & $62-67$ \\
\hline Prepectoral pores & 13 or 14 & 11 & $10-12$ & 14 & 15 & $13-15$ & $9-11$ \\
\hline Predorsal pores & $20-22$ & 58 & $57-64$ & - & 36 & $35-38$ & $37-44$ \\
\hline Preanal pores & $51-54$ & 55 & $52-67$ & - & 56 & $56-59$ & $62-69$ \\
\hline Infraorbital pores & $5+1$ & 6 & $5+1$ or 2 (mainly 6) & $5+1$ & $5+1$ & $5+1$ & $5+1$ \\
\hline Supraorbital pores & $1+4$ & 5 & $1+4$ or 5 (mainly 5) & $1+4$ & $1+4$ & $1+4$ & $1+4$ \\
\hline Mandibular pores & 7 & 5 & 5 or 6 (mainly 5) & 5 & 6 & 6 & 7 \\
\hline Preopercular pores & 2 & 2 & 2 & 2 & 2 & 2 & 2 \\
\hline Supratemporal pores & 3 & 3 & 3 & 3 & 3 & 3 & 3 \\
\hline Frontal pore & 1 & 1 & 1 & 1 & 1 & 1 & 1 \\
\hline
\end{tabular}


31'31.74"'E, 2.1 m, small otter trawl, 3 August 2010; Univ. of Malaya uncat. (2, 170 to $209 \mathrm{~mm}$ ), Malaysia, no other data.

Diagnosis: A species of Neenchelys distinguished by having a combination of the following characters: a robust body, its depth 19 to 32 times in TL; HL 7.8 to 8.5 in TL; snout pointed; pectoral fin well developed, longer than snout, 4.0 to 4.8 in HL; origin of dorsal fin relatively forward, 0.4 to 0.5 times HL behind gill opening; predorsal length 5.7 to 6.0 in TL; gill opening large, its height 6.8 to 8.5 in HL; teeth conical, slender, uniserial in jaws and vomer; total vertebrae 135 to 148 ; MVF 1950-140. Single median temporal and interorbital pores; supraorbital pores $1+4$; infraorbital pores $5+1$ ( 1 or 2 pores between anterior and posterior nostrils); mandibular pores 7; preopercular pores 2; supratemporal pores 3. Cephalic lateral line pores 13 or 14; predorsal pores 20 to 22; preanal pores 51 to 54 . Coloration in preserved specimens pale brown dorsally and paler ventrally, with black posterior portions of dorsal and anal fins.

Distribution and ecological notes: Known from the type material, captured in Indonesia, from Bombay, India (Mohamed 1958), and from a shallow-water $(<5 \mathrm{~m})$ mudflat at the bottom of a river mouth at Matang, western Malaysia (Ho et al. 2012).

Remarks: This species has received little attention since its original description which was based on a 129$\mathrm{mm}$ specimen from Java and another $(218 \mathrm{~mm})$ 'most probably from the Moluccas.' Their designation of a holotype is not clear. We herein recognize the larger syntype, ZMA.102.171 (218 mm TL), as the lectotype of $N$. buitendijki. Mohamed (1958) reported on 15 specimens (58.5 to $273 \mathrm{~mm} \mathrm{TL}$ ) collected along with shrimp at 8 to 10 fathoms ( 15 to $18 \mathrm{~m}$ ) from Bombay. Nelson (1966) extensively analyzed the osteology of specimens from Bombay and referred the species of Neenchelys to the subfamily Echelinae (=Myrophinae) of the Ophichthidae. Neenchelys buitendijki is most similar to $N$. parvipectoralis and $N$. microtretus in having a relatively short and stout body. It differs from them by having a pointed snout and well-developed pectoral fin. Mohamed (1958) gave 145 to 148 total vertebrae for his Indian specimens. However, all seven specimens we examined from Malaysia have slightly fewer total vertebrae, at only 135 to 140 . The difference may be attributable to geographic variation. More specimens from other localities in the Indo-west Pacific region are needed to understand the geographic variation of this species.

\section{Neenchelys cheni (Chen and Weng 1967)}

Common name: Chen's worm eel

(Figure 2A,B,C,D and Tables 1 and 2)

Synonymy: Myrophis cheni Chen and Weng 1967: 39, Figure twenty-nine (type locality: Tungkang, Taiwan);
Chen 2007:13. 'Neenchelys'cheni (Chen and Weng 1967): Ho et al. 2010: 24 (designation of lectotype). Neenchelys retropinna Smith and Böhlke 1983: 80, Figure one to three (type locality: Gulf of Oman). Paxton et al. 1989: 119; McCosker and Chen 2000: 356 (first record from Taiwan).

Material examined: Types: Myrophis cheni: Lectotype: NMMB-P3019, formerly THUP 3234 (350 mm), Tungkang Fishing Port, SW Taiwan, May 1966. Paralectotype: NMMB-P1534, formerly THUP 3328 (335 mm), Tungkang Fishing Port, SW Taiwan, September 1966. Neenchelys retropinna: holotype: ANSP $131512(320 \mathrm{~mm})$, ANTON BRUUN cruise 4-B, sta. 256-A, Gulf of Oman, $26^{\circ} 10^{\prime} \mathrm{N}$, 57 $02^{\prime}$ E, 55 to $64 \mathrm{~m}$, bottom trawl, 30 November 1963. Paratypes: ANSP 131513 (sex indeterminate, $289 \mathrm{~mm}$ ), same data as for ANSP 131512; AMS I. 21847-017 (sex indeterminate, $305 \mathrm{~mm}$ ), Arafura Sea, Australia, $10^{\circ} 02^{\prime} \mathrm{S}, 133^{\circ} 58^{\prime} \mathrm{E}, \mathrm{R} / \mathrm{V}$ SOELA, bottom trawl, 80 to 84 m, 17 November 1980.

Non-types: NMMB-P1535 (324 mm), Tungkang Fishing Port, SW Taiwan, 21 March 1979. NSYSU 3683 (386 mm), SW Taiwan, $22^{\circ} 32^{\prime} \mathrm{N}, 120^{\circ} 07^{\prime} \mathrm{E}, 50$ to $100 \mathrm{~m}$; TOU-AE 2850 (342 mm), Changbin, Taitung, E Taiwan, 31 July 2006, coll. M.-L. Chiou; TOU-AE 3535 (399 mm), Changbin, Taitung, E Taiwan, 8 February 2007, coll. M.-L. Chiou; NMMB-P12485 (376 mm), NMMB-P12486 (335 mm), NMMB-P12487 (338 mm), Da Nang, Vietnam, 9 April 2011; NMMB-P12491 (5, 381 to $414 \mathrm{~mm}$ ), Da Nang, Vietnam, 11 April 2011; NMMB-P12503 (3, 367 to 389 mm), NMMB-P12505 (335 mm), Da Nang, Vietnam, 9 April 2011.

Diagnosis: A species of Neenchelys distinguished by having a combination of the following characters: body moderately elongate and relatively compressed, depth at anus 3.3 to 5.2 times in HL, 29 to 40 in TL; HL 10.1 to 11.6 in TL; origin of dorsal fin relatively posterior, at about same vertical level as or slightly posterior to origin of anal fin, predorsal length 2.4 to 2.7 in TL; tail length 1.6 to 1.7 in TL; pectoral fin moderate in size, shorter than snout length, 7.0 to 7.8 in HL; snout relatively long, 4.1 to 5.2 in HL; total vertebrae 180 to 183 ; MVF 59-56181. Single median temporal and interorbital pores; supraorbital pores $1+4$ or $1+5$; infraorbital pores $5+1$ or $5+2$ ( 2 pores between anterior and posterior nostrils); mandibular pores 5 or 6 ; preopercular pores 2 ; supratemporal pores 3 . Cephalic lateral line pores 10 to 12; predorsal pores 57 to 64; preanal pores 52 to 67 . Coloration in preservative pale brown, slightly darker dorsally, fins pale except median fins which darken approximately one head length before the tail tip.

Distribution and ecological notes: Known from southern Taiwan, Vietnam, Australia (Paxton et al. 1989), and the Gulf of Oman (Smith and Böhlke 1983). In Taiwan, most specimens were collected by midwater trawl together 


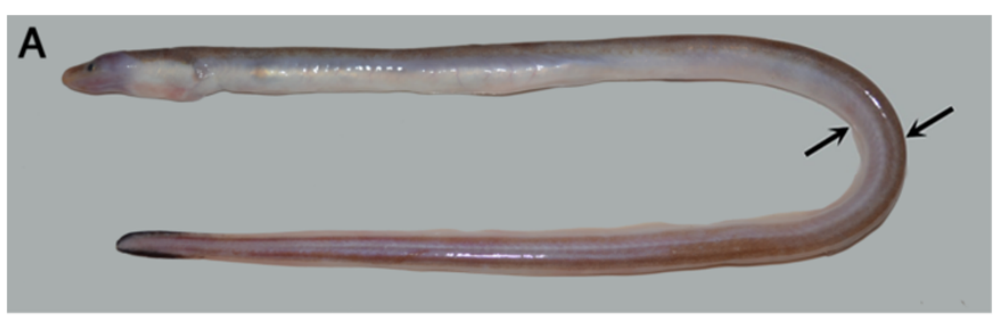

B
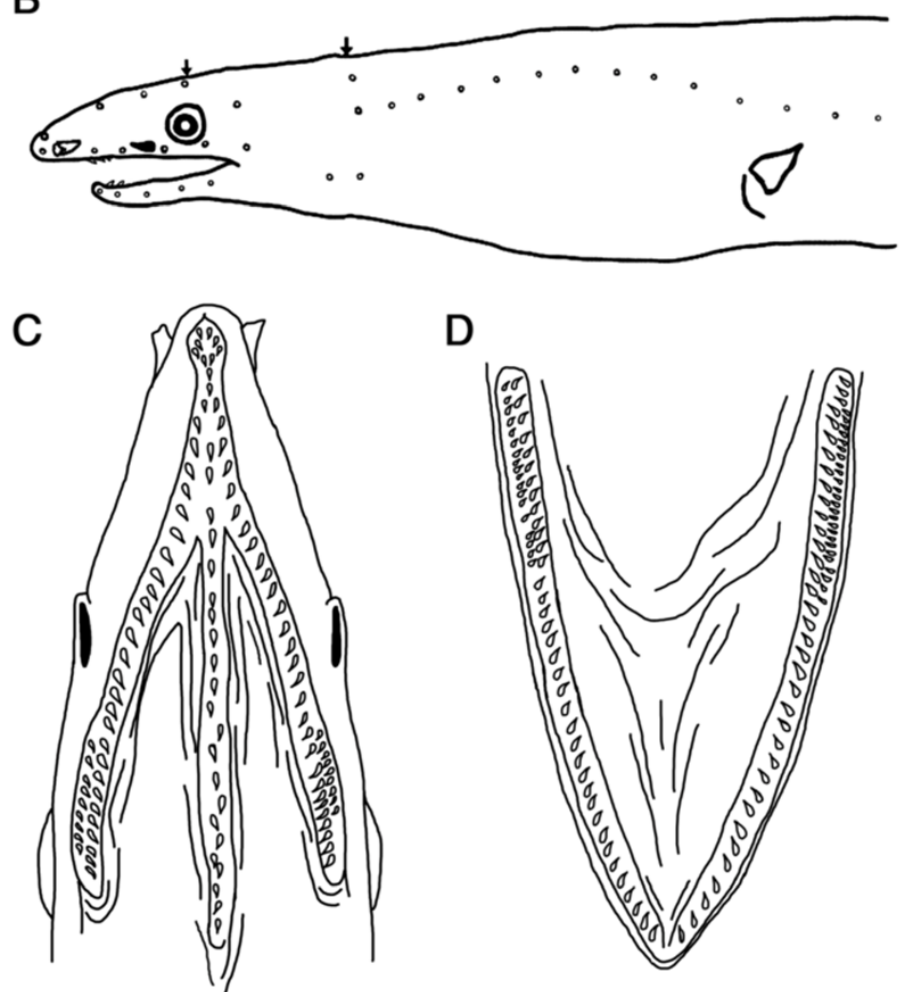

Figure 2 Neenchelys cheni (Chen and Weng 1967). (A) NMMB-P12505, 350 mm TL, Danang, Vietnam, with arrows indicating the origin of the dorsal fin (right) and anal fin (left), fresh condition. (B) Lateral view of the head, with arrows indicating the frontal pore (left) and median supratemporal pore (right). (C) Upper jaw teeth. (D) Lower jaw teeth. (B-D) From lectotype, NMMB-P3019, 350 mm TL.

with many mesopelagic fishes, suggesting that adults have a pelagic lifestyle. However, the type series of N. retropinna came from bottom trawls.

Remarks: The type specimens of $M$. cheni were rediscovered by Ho et al. (2010). They redescribed the two specimens, selected a lectotype, and referred the species to Neenchelys. They further stated that ' $N$. retropinna and "N." cheni are very likely conspecific.' Our examination of additional specimens supports their actions.

Smith and Böhlke (1983) mentioned that the maxillary teeth are uniserial in the type series of $N$. retropinna. However, there is one short outer row of smaller teeth along the posterior portion of the maxillary in the type series of $N$. cheni and in all Vietnamese specimens. It is notable that NSYSU 3683 has more complicated intermaxillary and vomerine dentition. There is one extra curved row of small teeth before the anterior intermaxillary tooth and many more teeth occupying the anterior palate, followed by two irregular series of vomerine teeth which gradually become uniserial posteriorly. That specimen is neither large nor small, and we are unable to assign significance to its dental condition.

Numbers of predorsal and preanal pores showed a higher variation than those of other species, especially the preanal pores (52 to 67). Based on our observations, the position of the dorsal fin origin is variable, slightly before or behind the anus, which the number of predorsal pores is highly related to. Although large variations of these two lateral line counts are atypical for ophichthids, our data suggest that $N$. cheni might have a larger variation of the preanal pore number than its congeners. 


\section{Neenchelys daedalus McCosker 1982}

Common name: New Guinea worm eel

(Figure 3A,B,C,D and Tables 1 and 2)

Synonymy: Neenchelys daedalus McCosker 1982: 63, Figure four (type locality: Astrolabe Bay, Papua New Guinea).

Material examined: Holotype: AMS I. 19690-012 (342 mm), Astrolabe Bay, Madang, Papua New Guinea $\left(05^{\circ} 24^{\prime} \mathrm{S}, 145^{\circ} 52.5^{\prime} \mathrm{E}\right)$. Paratype: CAS 50708 (272 mm), collected with holotype.

Diagnosis: A species of Neenchelys distinguished by having a combination of the following characters: body elongate and relatively compressed, its depth 46 to 52 times in TL; origin of dorsal fin at about midtrunk, 1.0 to 1.1 in HL behind gill opening; predorsal length 6.5 to 6.9 in TL; head 13 to 15 in TL, trunk 5.1 to 5.3 in TL; tail 1.3 to 1.8 in TL; pectoral fin elongate, nearly as long as upper jaw; teeth slender, conical, uniserial throughout; coloration uniformly tan, except belly which is dark brown to black, fins colorless; vertebrae 225 to 235 , MVF 31-58-230. Single median temporal and interorbital pores; supraorbital pores $1+4$; infraorbital pores; $5+1$ ( 2 pores between anterior and posterior nostrils); mandibular pores 5; preopercular pores 2; supratemporal pores 3. Body coloration in isopropyl alcohol uniformly tan, except belly which is dark brown to black; fins colorless.

Distribution and ecological notes: Known only from the type material, collected from Papua New Guinea by midwater trawl at 0 to $256 \mathrm{~m}$ over a 'rough peak > 500 fms [914 m] bottom' at 18:50 to 21:00.

Remarks: This species has not been correctly reported since its original description. It and species of Benthenchelys and perhaps two other congeners described herein are the

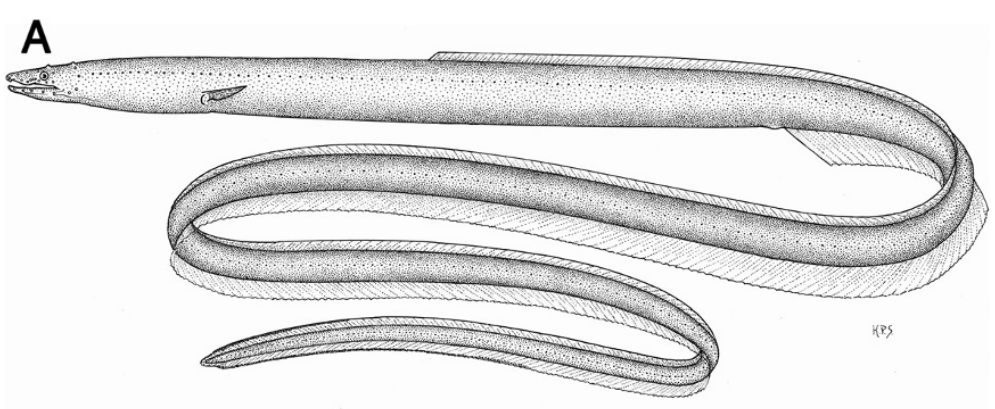

B

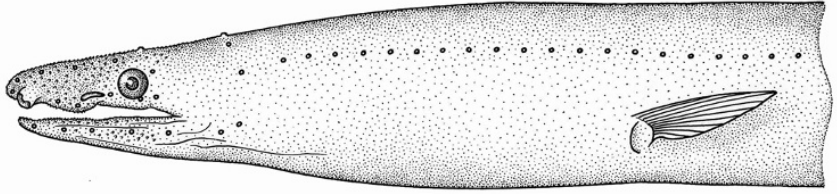

C

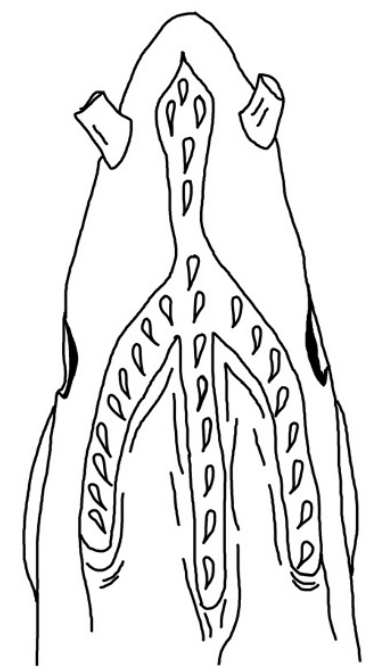

D

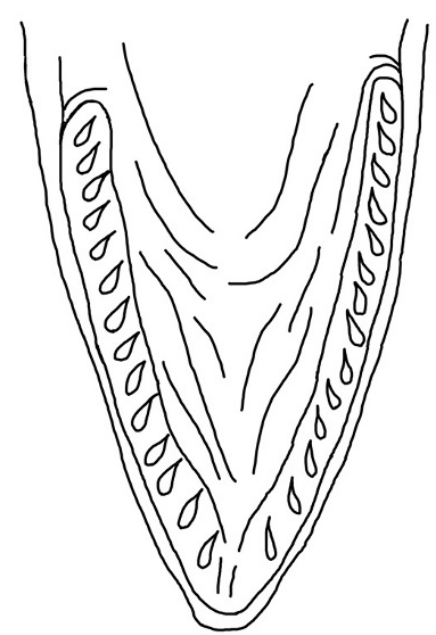

Figure 3 Neenchelys daedalus McCosker 1982. (A) Drawing of holotype. (B) Lateral view of head. (C) Upper jaw teeth. (D) Lower jaw teeth. (A, B) From AMS I. 19690-012, holotype, after McCosker (1982). (C, D) From CAS 50708, paratype, 272 mm TL. 
only ophichthids known to occupy the midwater realm as adults.

The original description of $N$. daedalus mentioned 11 other Pacific specimens from Papua New Guinea and the Banda Sea that were collected in midwater but differed in having more vertebrae. They were tentatively identified as $N$. daedalus; however, McCosker (1982: 65) treated them as non-paratypes and stated they are all smaller specimens and appear identical in proportions to the new species. They differ considerably, however, in total vertebral numbers: the holotype and paratype have 235 and 225, respectively, whereas eight of the others had 251-274 (mean $=266.8$ ) vertebrae. I am unable to account for such a large mean vertebral difference and broad range in vertebral number for conspecifics in such close geographical proximity, and therefore have not made them type-specimens.' We now recognize that these belong to a new species, Neenchelys similis sp. nov., which is described in this revision.

\section{Neenchelys diaphora sp. nov.}

Common name: Longfin worm eel

(Figure 4A,B,C,D,E and Tables 1 and 2)

Holotype: NMMB-P17563 (475 mm), a ripe female, Tungkang Fishing Port, SW Taiwan, northern South China Sea, otter trawl, 25 November 2011.

Paratype: NMMB-P16304 (430 mm), a ripe female, Tungkang Fishing Port, SW Taiwan, northern South China Sea, otter trawl, 19 March 2012, coll. H.-C. Ho; NMMB-P17553 (264 mm), sex indeterminate, Tungkang Fishing Port, SW Taiwan, northern South China Sea, otter trawl, 9 November 2012, coll. H.-C. Ho.

Etymology: From the Greek diaphoros, meaning different. Initially, the holotype was recognized as being closely similar to Neenchelys pelagica sp. nov. described below. With the newly collected specimens, we were able to confirm its differentiation and describe it as a new species.

Diagnosis: A species of Neenchelys distinguished in having a combination of the following characters: body relatively cylindrical, 2.8 to 3.3 times in HL, 28 to 35 in TL; dorsalfin origin at midpoint of trunk, 1.2 to 1.5 times in HL behind gill opening; predorsal length 4.4 to 4.6 in TL; HL 9.9 to 10.8 in TL; tail 1.5 to 1.6 in TL; pectoral fin well developed and relatively large, 3.7 to 4.0 in HL; total vertebrae 177 to 186 ; MVF 35-54-181. Cephalic lateral line pores 13 to 15 ; predorsal pores 35 to 38; preanal pores 56 to 59 .

Description: Morphometric and meristic data are provided in Tables 1 and 2. The following proportions are given for the holotype, followed by values of the paratypes in parentheses. In TL: HL 9.9 (9.9 to 10.8); predorsal length 4.4 (4.4 to 4.6); trunk length 4.0 (3.8 to 4.2 ); preanal length 2.8 (2.8 to 3.0 ); tail length 1.5 (1.5 to 1.6 ).
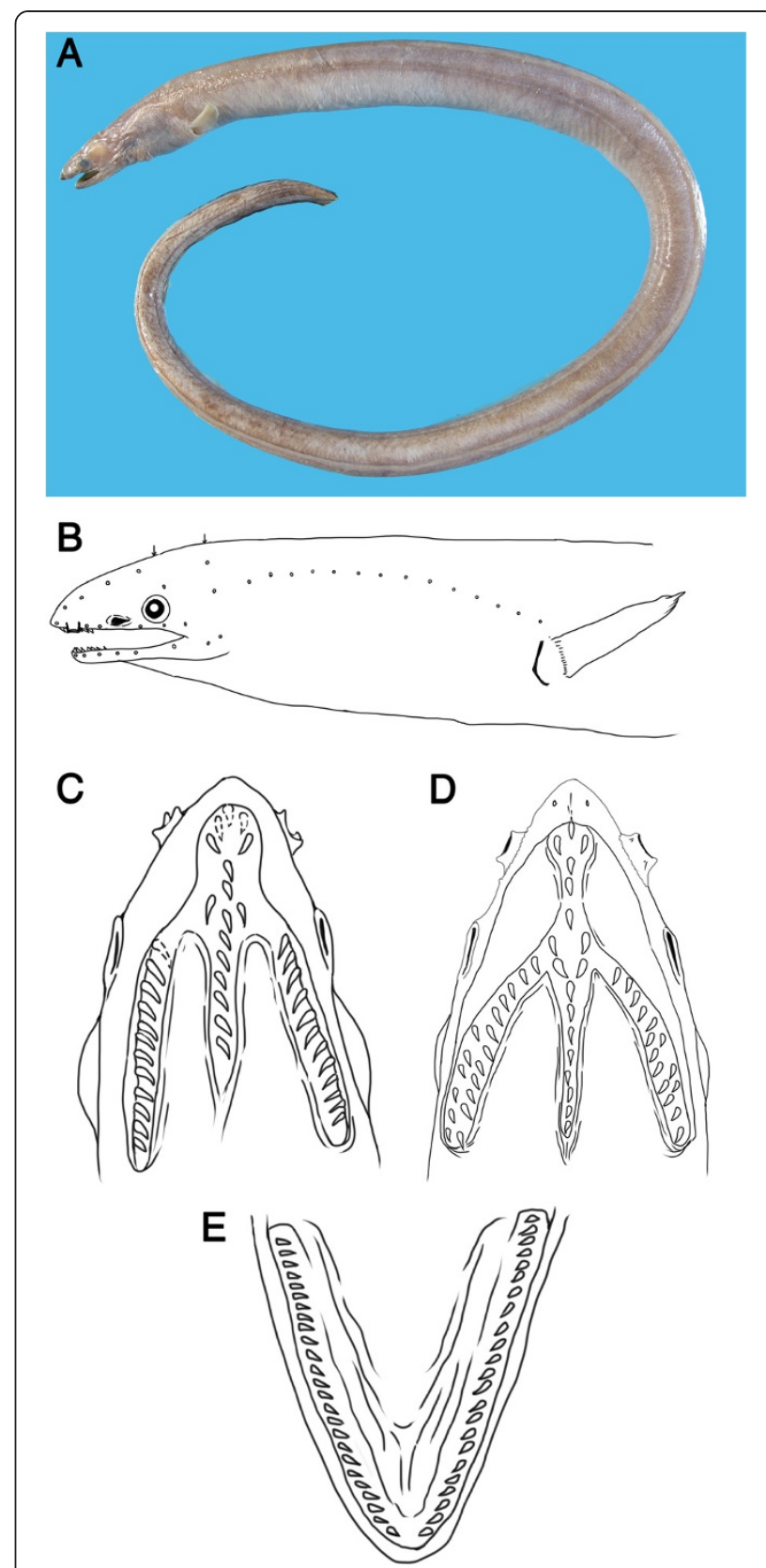

Figure 4 Neenchelys diaphora sp. nov. (A) Dorsal-lateral view of holotype, NMMB-P17563, 475 mm TL. (B) Lateral view of head.

(C, D) Upper jaw teeth. (E) Lower jaw teeth. (C, E) From holotype. (B, D) From NMMB-P16304, paratype, $430 \mathrm{~mm}$ TL.

In HL: pectoral fin length 3.7 (3.7 to 4.0); snout length 5.2 (5.2 to 5.3 ); eye diameter 15.2 (14.8 to 16.3 ); upper jaw length 3.4 (3.2 to 3.4); interorbital width 7.3 (6.9 to 7.5 ); gill opening height 8.0 (8.0 to 11.3 ); body depth at gill opening 2.8 (2.8 to 3.3); body depth at anus 2.6 (2.0 to 3.1 ); body width at anus 3.0 (2.7 to 3.7 ).

Body moderately elongate; somewhat cylindrical with tail gradually compressed posteriorly; depth of body 
relatively uniform, tapering gradually to tail tip; depth of head subequal to that of body. Tail moderately long, anus at anterior $1 / 3$ of body length. Dorsal and anal fins low and fleshy, continuous with a small but distinct rayed caudal fin; origin of dorsal fin about one HL before a vertical through origin of anal fin. Pectoral fin relatively well developed, broad at base, and pointed posteriorly.

Head profile terete; snout acute anteriorly, tip of snout projecting well beyond lower jaw. Anterior nostril tubular, directed anteroventrally, its tube distinctly notched dorsally. Posterior nostril in front of lower margin of eye, opening directed ventrally, appearing in lateral aspect as a diagonal slit, the posterior end of which is highest. Behind and below nostril and parallel to it with a groove that is longer than nasal slit. Snout broad and tumid, housing an extensive nasal organ on either side. Lower jaw included, its tip reaching a line between anterior margins of anterior nostrils. Angle of gape about one eye diameter behind a vertical through posterior margin of pigmented eyeball. Tongue not free, well attached to mouth floor. Gill opening a narrow vertical slit, situated at anteroventral corner of pectoral fin base.

Head pores small (Figure 4B), single median temporal and interorbital pores. Supraorbital pores $1+4$; infraorbital pores $5+1$ (2 pores between anterior and posterior nostrils). Mandibular pores 6; preopercular pores 2; supratemporal pores 3 .

Teeth slender (Figure 4C,D,E), pointed, tips directed posteriorly, anteriormost one in each series longest. Intermaxillary teeth 5 (3 to 5 ), well separated from that of vomer; vomerine teeth uniserial, with 1 (1 or 2 ) pair of side teeth between second and third (or first and second) teeth, terminating posteriorly before end of maxillary tooth row (Figure 4C; about same level in 430-mm paratype, Figure 4D); maxillary uniserial (two irregular rows in 430-mm paratype, Figure 4D), with 12 (10 to 12) teeth, terminating posteriorly at gape; dentary with 23 to 25 (21 to 25 ) uniserial teeth, its end terminating at that of opposite maxillary tooth row.

Lateral line incomplete, pores small and inconspicuous, extending to about one HL before caudal fin. Cephalic lateral line pores 15 (13 to 15 ), predorsal pores 36 (35 to 38 ), and preanal pores 56 (56 to 59 ).

Coloration when fresh uniformly brownish gray with posterior end of dorsal and anal fin margins edged black; in preservative gray to light brown, with posterior end of dorsal and anal fins edged black.

Distribution and ecological notes: Known from the type series collected from SW Taiwan, the northern portion of the South China Sea. Specimens were collected together with $N$. parvipectoralis and $N$. mccoskeri, indicating that this species may have a benthic lifestyle and probably feeds on benthic fishes and/or invertebrates.
Remarks: Neenchelys diaphora sp. nov. is most similar to $N$. pelagica sp. nov. described below in having a similar appearance and proportional measurements. It differs from $N$. pelagica sp. nov. by having a total of 177 to 186 vertebrae $(n=4)$ (vs. $169 ; n=3)$, a relatively large gill opening ( $8.8 \%$ to $12.6 \%$ vs. $6.6 \%$ to $7.9 \% \mathrm{HL})$; six mandibular pores (vs. seven); and a benthic (vs. pelagic) life style. It is also similar to those species with well-developed pectoral fins, i.e., N. cheni, N. daedalus, and $N$. buitendijki. It differs from $N$. cheni by the dorsal fin origin being situated at the midpoint of the trunk (vs. above the anus), a larger pectoral fin, and an MVF of 35-54-181 (vs. 59-56-181). It differs from $N$. daedalus by having a relatively stouter body (body depth 28 to 35 vs. 46 to 52 in TL), an MVF of 35-54-181 (vs. 31-58-230), and different body proportions (see Table 1). It differs from $N$. buitendijki by having a relatively rounded snout (vs. pointed), an MVF of 35-54-181 (vs. 19-50-140), and different body proportions (see Table 1). Neenchelys diaphora sp. nov. is also similar to $N$. mccoskeri in general appearance but differs in having a well-developed pectoral fin (vs. a minute pectoral fin) and an MVF of 35-54181 (vs. 37-65-179).

\section{Neenchelys mccoskeri Hibino, Ho and Kimura 2012}

Common name: McCosker's worm eel

(Figure 5A,B,C,D and Tables 1 and 2)

Synonymy: Neenchelys mccoskeri Hibino, Ho and Kimura 2012: 343, Figures one to three (type locality: Tungkang Fishing Port, SW Taiwan).

Material examined: Holotype: NMMB-P 15557 (512 mm), male, Tungkang Fishing Port, SW Taiwan, 28 February 2011, bottom trawl, collected by H.-C. Ho. Paratypes: Taiwan: Tashi, NW Taiwan: ASIZP 60870 (449 mm), 25 February 2000, coll. J.-X. Wang; Tungkang Fishing Port, SW Taiwan: ASIZP 70422 (324 mm), 1 July 2001, coll. P.-L. Lin; CAS 231943 (324 mm), female with immature ova, collected with holotype; NMMB-P2915 (300 mm), 21 March 1979; NMMB-P11541 (3, 298 to $371 \mathrm{~mm}$ ), bottom trawl, 10 September 2009; NMMBP11542 (492 mm), bottom trawl, 10 December 2010; NMMB-P11543 (290 mm), bottom trawl, 28 January 2011; NMMB-P12001 (298 mm), bottom trawl, 18 February 2011; NMMB-P13721 (365 mm), bottom trawl, 13 September 2011; NMMB-P15544 (385 mm), bottom trawl, 1 March 2011; NMMB-P15545 (4, 300 to $381 \mathrm{~mm})$, bottom trawl, 2 July 2011; NMMB-P15546 (358 mm), bottom trawl, 10 August 2011; NMMB-P15547 (8, 292 to $522 \mathrm{~mm}$ ), bottom trawl, 20 October 2011; NMMBP15548 (4, 280 to $353+\mathrm{mm})$, bottom trawl, 25 October 2011; NMMB-P 15549 (3, 394 to $503 \mathrm{~mm}$ ), bottom trawl, 28 January 2012; USNM 398566 (412 mm), 14 November 2009, coll. D.G. Smith and H.-C. Ho; USNM 400343 

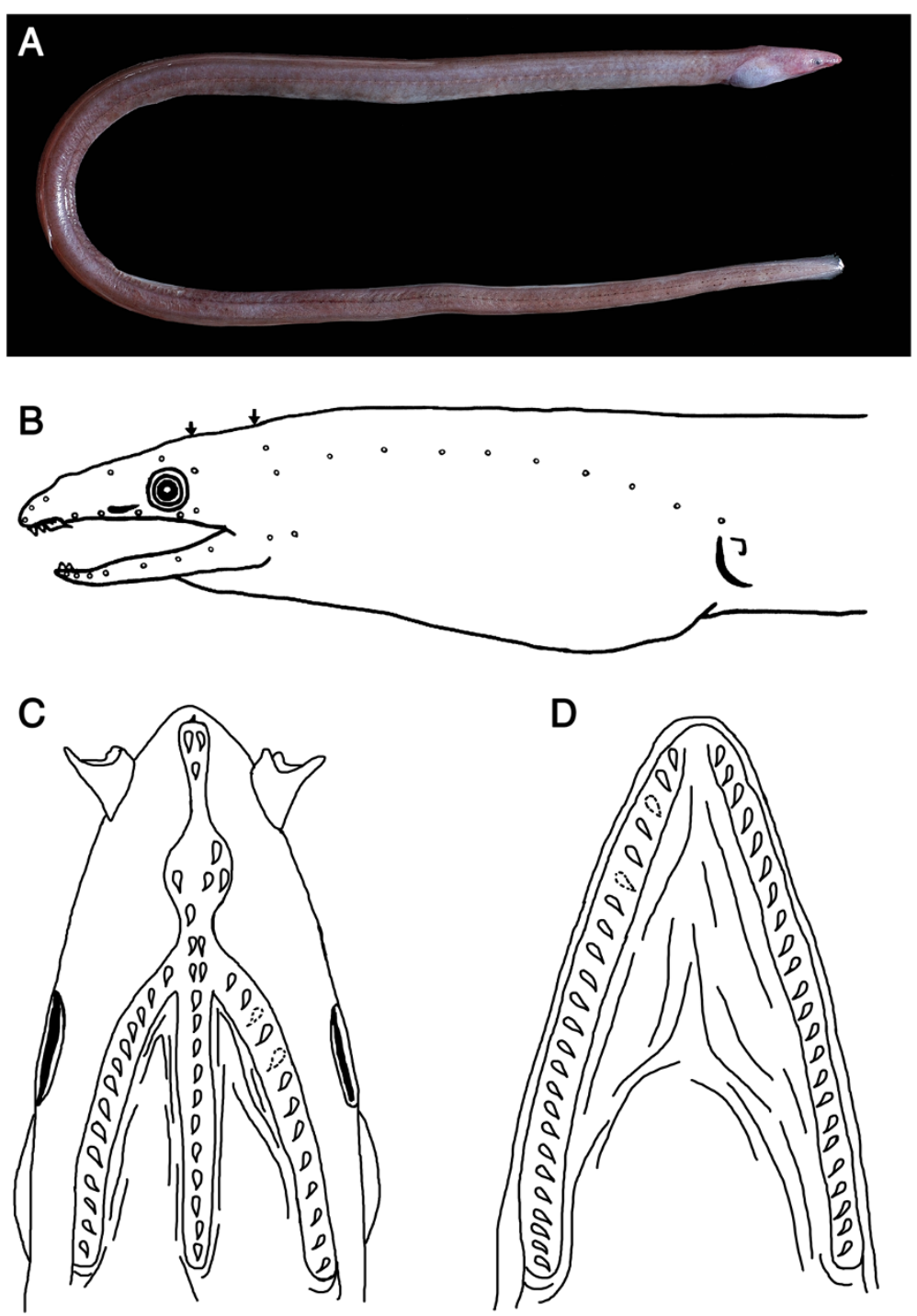

Figure 5 Neenchelys mccoskeri Hibino, Ho and Kimura 2012. (A) NMMB-P15542, paratype, 492 mm TL, Tungkang, Taiwan, fresh condition. (B) Lateral view of head, with arrows indicating the frontal pore (left) and median supratemporal pore (right). (C) Upper jaw teeth. (D) Lower jaw teeth. (B-D) From NMMB-P 15557, holotype, 512 mm TL.

(430 mm), 8 November 2009, coll. D.G. Smith and H.-C. Ho; USNM 401023 (413 mm), 28 February 2011, coll. D. G. Smith and H.-C. Ho; USNM 401029 (374 mm), collected with USNM 400343. Other material: NSYSU 3682 (2, 317, $356 \mathrm{~mm})$, Tungkang Fishing Port, SW Taiwan, bottom trawl, April 1999.

Diagnosis: A species of Neenchelys distinguished in having a combination of the following characters: robust body, its depth 31 to 87 times in TL; HL 13.0 to 15.6 in TL; snout pointed; pectoral fin minute, a tiny transparent flap; a pointed appendage on posterior rim of anterior nostril; origin of dorsal fin at middle of trunk, 2.0 to 2.7 times in HL behind gill opening; predorsal length 3.8 to 4.8 in TL; gill opening small, its height 9.9 to 15.8 in $\mathrm{HL}$; teeth conical, slender, uniserial in jaws and vomer; total vertebrae 172 to 184 ; MVF 37-65-179. Single median temporal and interorbital pores; supraorbital pores $1+4$; infraorbital pores $5+1$ or $5+2$ ( 2 pores between anterior and posterior nostrils); mandibular pores 6 or 7; preopercular pores 2; supratemporal pores 3. Cephalic lateral line pores 9 to 11; predorsal pores 37 to 44; preanal pores 62 to 69 . Coloration when fresh, head brown anteriorly, body pinkish gray with black posterior end of median fin margins; when preserved, head and body entirely pale gray to brown with scattered melanophores dorsally; fins colorless, but edge of posterior dorsal and anal fins blackish.

\section{Neenchelys microtretus Bamber 1915}

Common name: Small-fin worm eel 
(Figure 6 and Tables 3 and 4)

Synonymy: Neenchelys microtretus Bamber 1915: 479, pl. 46, Figure three (type locality: Suez).

Material examined: Holotype: BMNH 1915.10.25.1 (183 mm), Suez, Egypt, Gulf of Suez, Red Sea.

Diagnosis: Body robust, its depth 26 times in TL; pectoral fin minute, about equal to eye; origin of dorsal fin about 3/4 HL behind gill opening, well in advance of level of anus; head about 9.2 in TL; tail 1.7 in TL; teeth slender, conical, uniserial throughout; vertebral formula 24-56-151. Single median temporal and interorbital pores; supraorbital pores $1+4$; infraorbital pores $5+1$ (2 pores between anterior and posterior nostrils); mandibular pores 5; preopercular pores 2; supratemporal pores 3 . Coloration when preserved 'uniform (in spirit)' (cf. Bamber 1915: 479).

Distribution: Known only from holotype, collected from the Rea Sea.

Remarks: This species remains known only from the holotype. The original description was very brief and lacked measurements other than the TL (as '185 mm'). One of us (JM) examined the fragile type specimen and obtained the following measurements (in $\mathrm{mm}$ ): TL 183, HL 20, trunk length 57 , tail length 106 , dorsal fin origin 35 , snout $\sim 3.5$, jaw $\sim 5.5$, eye $\sim 1.0$, depth behind gill openings $\sim 7$. This species is extremely similar to the subsequently described species, $N$. parvipectoralis. It may prove to be a senior synonym of $N$. parvipectoralis when more specimens become available.

\section{Neenchelys parvipectoralis Chu, Wu and Jin 1981}

Common name: Mini-fin worm eel

(Figure 7A,B,C,D and Tables 3 and 4)

Synonymy: Neenchelys parvipectoralis $\mathrm{Chu}, \mathrm{Wu}$ and Jin 1981: 24, Figures four to five (type locality: Pingtan Island, Fujian Province, China); Ho et al. 2010: 29 (description of Taiwanese specimens).

Material examined: Holotype: ASIZB 73634 (formerly Shanghai Fishery University A01383) (tail partially broken), Pingtang Island, Fujian Prov., China. Non-types: China: ASIZB 29188 (112 mm), Nan-ao, Canton [Guangzhou],
11 March 1954; ASIZB 50977 (120 mm), Xan-wei, Canton, 16 October 1956; ASIZB 73631 (118 mm), South China Sea, 1956; ASIZB 73633 (123 mm), South China Sea, 1956; SFC 11619 (155 mm), Pingtang Island, Fuqing, March 1976; SFC 7-4978-1 (177 mm), Shawei, Fuqing, November 1963; SFC 14031 (147 mm), Pingtang, Fuqing, no date. Taiwan (all specimens from Tungkang Fishing Port, SW Taiwan): NMMB-P2912 (6, 163 to $238 \mathrm{~mm})$, no date; NMMB-P11145 (8, 228 to $302 \mathrm{~mm}), 4$ September 2008; NMMB-P11146 (175 mm), 30 October 2010; NMMB-P11977 (158 mm), 28 January 2011; NMMB-P13732 (64, 195 to $285 \mathrm{~mm}), 13$ September 2010; NMMB-P13780 (3, 179 to $241 \mathrm{~mm}$ ), 21 July 2011; NMMB-P13839 (275 mm), 5 October 2010; NMMB-P14019 (2, 157 to $281 \mathrm{~mm}), 6$ September 2011; NMMBP14076 (4, 166 to $202 \mathrm{~mm}$ ), 10 August 2011; NMMBP14245 (17, 220 to $290 \mathrm{~mm}), 6$ September 2011; NMMB-P15551 (32, 198 to 290 mm), 2 July 2011; USNM 398480 (233 mm), 12 November 2009; USNM 398509 (252 mm), 12 November 2009; USNM 399863 (228 mm), 8 November 2009; USNM 399945 (6, 155 to $240 \mathrm{~mm}$ ) November 2009. Vietnam: ASIZP 71605 (328 mm) Nha Trang, 16 April 2009; ASIZP 71608 (282 mm), Nha Trang, 18 April 2009; NMMB-P12501 (261 mm), Da Nang, 9 April 2011; NMMB-P12477 (4, 202 to $226 \mathrm{~mm}$ ), Phen Thiet, 25 November 2010.

Diagnosis: A species of Neenchelys distinguished by the combination of the following characters: stout and cylindrical body, depth at gill openings 23 to 29 times in TL, 1.7 to 3.0 in HL; pectoral fin minute, a small transparent flap; origin of dorsal fin in anterior trunk region, 0.5 to 0.7 in HL behind gill opening, predorsal length 5.7 to 6.4 in TL; HL 8.8 to 9.9 in TL; tail 1.6 to 1.8 in TL; a slender pointed appendage on lower rim of anterior nostril; total vertebrae 138 to 148; MVF 20-55-143. Single median temporal and interorbital pores; supraorbital pores $1+4$; infraorbital pores $5+1$ ( 2 pores between anterior and posterior nostrils); mandibular pores 6 or 7 (mainly 6); preopercular pores 1 or 2 (mainly 1 ); supratemporal pores 3. Cephalic lateral line pores 12 to 14 ; predorsal pores 19 to 24 ; preanal pores 53 to 59 . Coloration

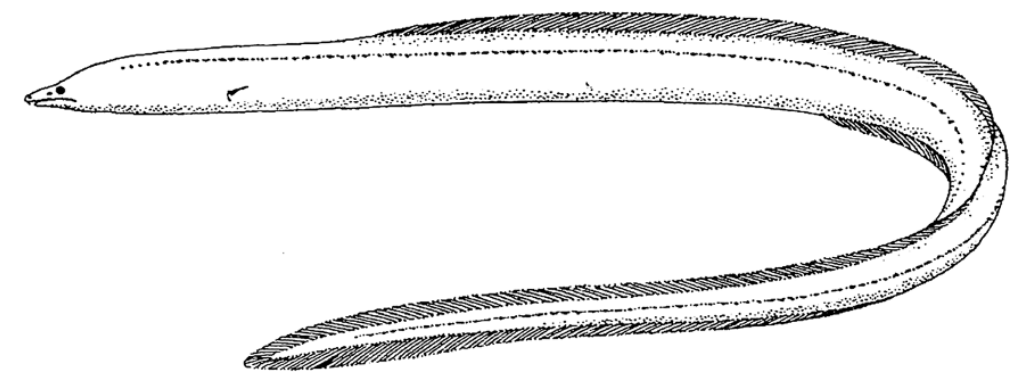

Figure 6 Neenchelys microtretus Bamber 1915, original drawing of holotype, after Bamber (1915). 
Table 3 Morphometric data of four Neenchelys species, expressed as percentage of total length, trunk length, and head length

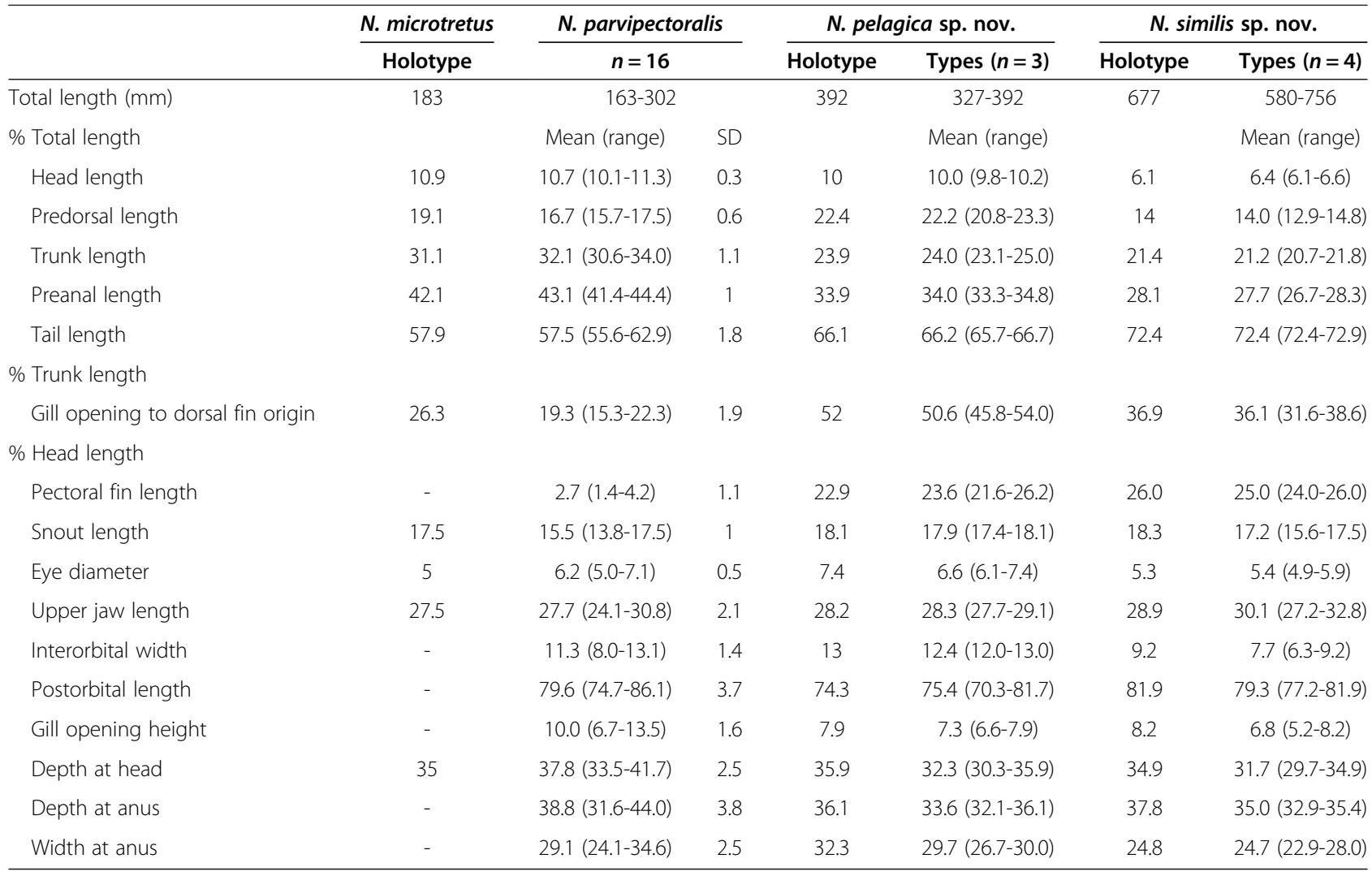

uniformly pinkish yellow when fresh, creamy white when preserved, posterior margins of median fins blackened.

Distribution and ecological notes: Known from southern coasts of China and southern Taiwan. Specimens were recently collected from Vietnam off Nha Trang, Da Nang, and the Mekong River mouth area (the latter according to 11 April 2011 correspondence from
K. Shibukawa, Nagao Natural Environment Foundation, Tokyo, Japan). The localities and method of capture suggest that this species is demersal, inhabiting depths of $<300 \mathrm{~m}$. A $237-\mathrm{mm}$ specimen (NMMBP2912) with fully ripe eggs suggests that this is a small species. The largest specimen examined was $328 \mathrm{~mm}$ TL.

Table 4 Meristic data of four Neenchelys species treated in present study

\begin{tabular}{|c|c|c|c|c|c|c|}
\hline & \multirow{2}{*}{$\frac{\text { N. microtretus }}{\text { Holotype }}$} & \multirow{2}{*}{$\frac{\text { N. parvipectoralis }}{n=41}$} & \multicolumn{2}{|c|}{ N. pelagica sp. nov. } & \multicolumn{2}{|c|}{ N. similis sp. nov. } \\
\hline & & & Holotype & Types $(n=3)$ & Holotype & Types $(n=4)$ \\
\hline Total vertebrae & 151 & $138-148$ & 169 & 169 & 261 & $260-265$ \\
\hline Predorsal vertebrae & 24 & $18-23$ & 31 & $31-34$ & 32 & $32-36$ \\
\hline Preanal vertebrae & 56 & $53-57$ & 53 & $52-54$ & 68 & $68-70$ \\
\hline Prepectoral pores & - & $12-14$ & 14 & 14 & 16 & 15 or 16 \\
\hline Predorsal pores & - & $19-24$ & 36 & 36 or 37 & 36 & $35-37$ \\
\hline Preanal pores & - & $53-59$ & 57 & 56 or 57 & 71 & 70 or 71 \\
\hline Infraorbital pores & $5+1$ & $5+1$ & $5+1$ & $5+1$ & $5+1$ & $5+1$ \\
\hline Supraorbital pores & $1+4$ & $1+4$ & $1+4$ & $1+4$ & $1+4$ & $1+4$ \\
\hline Mandibular pores & 5 & 6 or 7 (mainly 6) & 7 & 7 & 7 & 7 \\
\hline Preopercular pores & 2 & 1 or 2 (mainly 1 ) & 2 & 2 & 2 & 2 \\
\hline Supratemporal pores & 3 & 3 & 3 & 3 & 3 & 3 \\
\hline Frontal pore & 1 & 1 & 1 & 1 & 1 & 1 \\
\hline
\end{tabular}



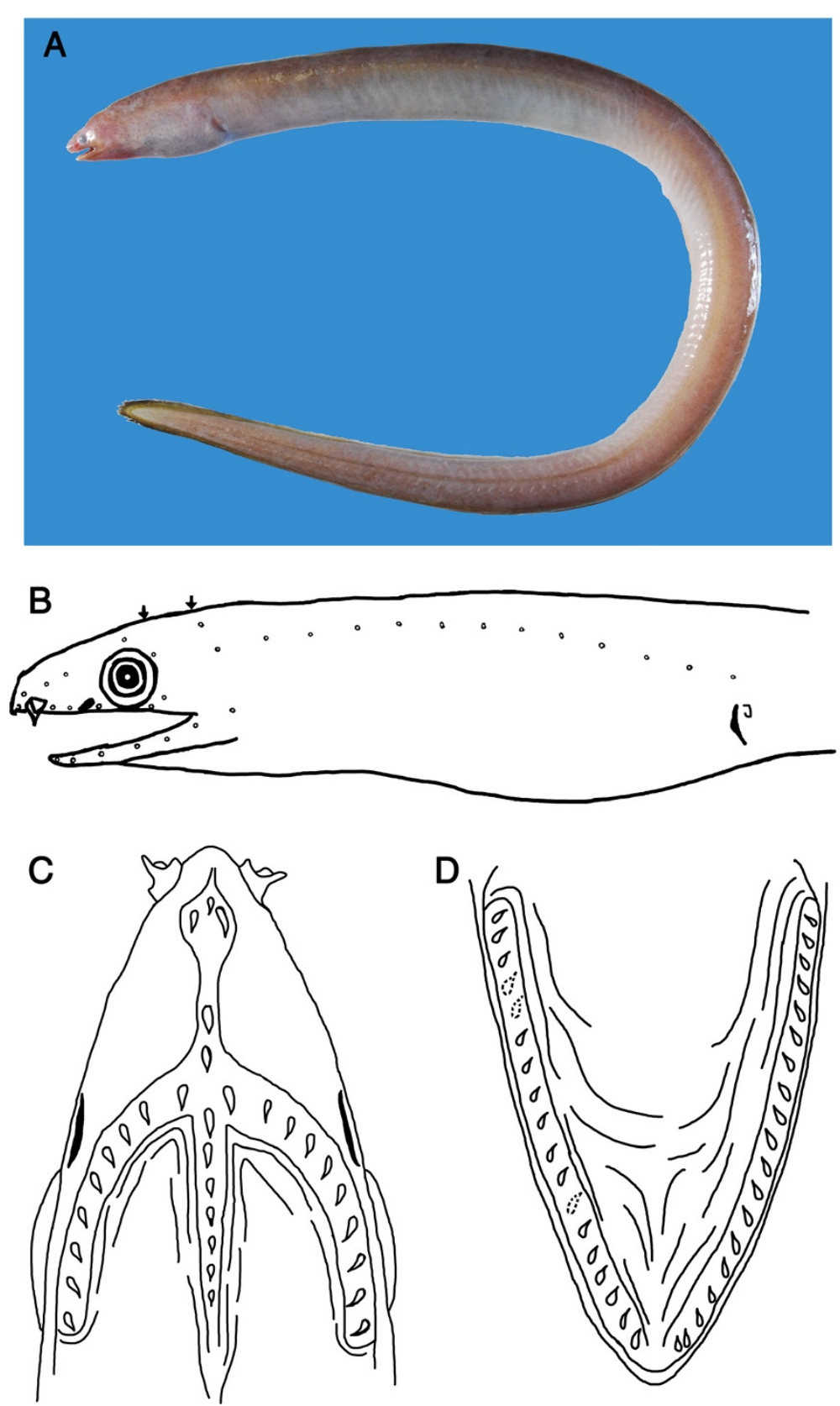

Figure 7 Neenchelys parvipectoralis Chu, Wu and Jin 1981. (A) NMMMB-P15551, 290 mm TL, Tungkang, Taiwan, fresh condition. (B) Lateral view of head, with arrows indicating the frontal pore (left) and median supratemporal pore (right). (C) Upper jaw teeth. (D) Lower jaw teeth. (B-D) From NMMB-P15551, 238 mm TL.

Remarks: This species was only known from the holotype collected from Pingtan Island, China, until Ho et al. (2010: 29) redescribed it on the basis of six specimens from Taiwan. Additional specimens were collected in southern Taiwan and Vietnam by bottom trawling at 100 to $300 \mathrm{~m}$ in depth. The first author also examined three specimens (SFC 11619, SFC 7-4978-1, and SFC 14031) labeled as paratypes of $N$. parvipectoralis. The original description (Chu et al. 1981) was stated to be based on a single specimen; however, we presume that the authors examined these three additional specimens, which were also not treated as types by Chu et al. (1981).

As stated earlier in this paper, we were unable to differentiate between $N$. parvipectoralis and $N$. microtretus. The vertebral difference between the two species $(N$. microtretus 151 vs. N. parvipectoralis 138 to 148) is minor but might be significant. The only known specimen of $N$. microtretus from the Red Sea has a vertebral 
count beyond the range of Asian specimens of $N$. parvipectoralis. Considering the frequency of endemism in the Red Sea, we think this may be significant. The holotype of $N$. microtretus is a small, damaged specimen. Because these two taxa come from such disparate locations, we await adequate material of both species before a determination can be made.

\section{Neenchelys pelagica sp. nov.}

Common name: Pelagic worm eel

(Figure 8A,B,C,D and Tables 3 and 4)

Holotype: NMMB-P15556 (392 mm), a ripe female, Tungkang Fishing Port, SW Taiwan, northern South China Sea, midwater shrimp trawl, 10 September 2009, coll. H.-C. Ho.

Paratypes: CAS 231943 (327 mm), a ripe female, USNM $401022(353 \mathrm{~mm})$, a fully ripe female, collected together with the holotype.

Etymology: From the Latin pelagica, in reference to its mesopelagic habitat.

Diagnosis: A species of Neenchelys distinguished by the combination of the following characters: body moderately elongate, relatively cylindrical, body depth 2.8 to 3.1 times in $\mathrm{HL}, 28$ to 31 in $\mathrm{TL}$; dorsal fin origin at midpoint of trunk, 1.0 to 1.4 times in HL behind gill opening; predorsal length 4.3 to 4.8 in TL; HL 9.8 to 10.2 in TL; tail 1.5 in TL; pectoral fin well developed and relatively large, 3.8 to 4.6 in HL; total vertebrae 169; MVF 33-53-169. Cephalic lateral line pores 14; predorsal pores 36 or 37; preanal pores 56 or 57 .

Description: Morphometric and meristic data are provided in Tables 3 and 4. The following proportions are given for the holotype, followed by values of the type series in parentheses. In TL: HL 10.0 (9.8 to 10.2); predorsal length 4.5 (4.3 to 4.8 ); trunk length 4.2 (4.0 to 4.3); preanal length 2.9 (2.9 to 3.0); tail length 1.5 (1.5). In HL: pectoral fin length 4.4 (3.8 to 4.6); snout length 5.5 (5.5 to 5.7 ); eye diameter 13.6 (13.6 to 16.5 ); upper jaw length 3.5 (3.4 to 3.6); interorbital width 7.7 (7.7 to 8.3); gill opening height 12.7 (12.7 to 15.1 ); body depth at gill opening 27.8 (27.8 to 33.6 ); body depth at anus 2.8 (2.8 to 3.1); body width at anus 3.1 (3.1 to 3.7).

Body moderately elongate, somewhat cylindrical, tail gradually compressed posteriorly; depth of body relatively uniform, tapering gradually to tail tip; depth of head subequal to that of body. Tail moderately long, anus at first $1 / 3$ of body length. Dorsal and anal fins low and fleshy, continuous with a small but distinctly rayed caudal fin; origin of dorsal fin about one HL before a vertical through origin of anal fin. Pectoral fin relatively well developed, broad at base and pointed distally.

Head profile terete; snout acute anteriorly, tip of snout projecting well beyond lower jaw. Anterior nostril tubular, directed anteroventrally, its tube distinctly notched dorsally. Posterior nostril in front of lower margin of eye, opening directed ventrally, appearing in lateral aspect as a diagonal slit, the posterior end of which is highest. Behind and below nostril and parallel to it with a groove that is longer than nasal slit. Snout broad and tumid. Lower jaw included, its tip reaching a line drawn between anterior margins of anterior nostrils. Angle of gape about one eye diameter behind a vertical through posterior margin of pigmented eyeball. Tongue well attached to mouth floor. Gill opening a narrow vertical slit, situated at anteroventral corner of pectoral fin base.

Head pores small (Figure 8B). Single median temporal and interorbital pores; supraorbital pores $1+4$; infraorbital pores $5+1$ ( 2 pores between anterior and posterior nostrils). Mandibular pores 7; preopercular pores 2; supratemporal pores 3 .

Teeth slender (Figure 8C,D), pointed, tips directed posteriorly, anteriormost one in each series longest. Intermaxillary teeth 2 (2 or 3), well separated from that of vomer; vomerine teeth 8 (7 or 8 ), uniserial, with a pair of side teeth between second and third teeth, terminating posteriorly before end of maxillary tooth row; maxillary with 12 to 15 (10 to 15) small uniserial teeth, terminating posterior to gape; dentary with 19 to 21 (17 to 21) small uniserial teeth, terminating opposite end of maxillary teeth.

Lateral line incomplete, pores small and inconspicuous, extending to about one HL before caudal fin. Cephalic lateral line pores 14; predorsal pores 36 or 37; preanal pores 56 or 57.

Coloration: When fresh, pale gray with posterior end of dorsal and anal fin margins edged in black; in preservative, pale gray to light brown, with posterior end of dorsal and anal fins edged in black.

Distribution and ecological notes: Known from the type series collected from SW Taiwan, the northern portion of the South China Sea. Specimens were collected together with several mesopelagic fishes (myctophids, nemichthyids, nettastomatids, and Harpadon spp.), indicating that this species, like $N$. daedalus, may have a mesopelagic lifestyle and probably feeds on mesopelagic fishes and/or invertebrates.

Remarks: Neenchelys pelagica sp. nov. is most similar to $N$. diaphora sp. nov. described above. For a detailed comparison, see that of $N$. diaphora sp. nov. Neenchelys pelagica sp. nov. is also similar to $N$. cheni, $N$. daedalus, and $N$. buitendijki in having a well-developed pectoral fin. It differs from $N$. cheni by the dorsal fin origin being situated at midtrunk (vs. about above the anus), a larger pectoral fin, and an MVF of 33-53-169 (vs. 59-56-181). It differs from $N$. daedalus by having a more robust body (body depth 28 to 34 in TL vs. 46 to 52 in TL), an MVF of 33-53-169 (vs. 31-58-230), and different body proportions (see Tables 1 and 3). It differs from $N$. buitendijki by 

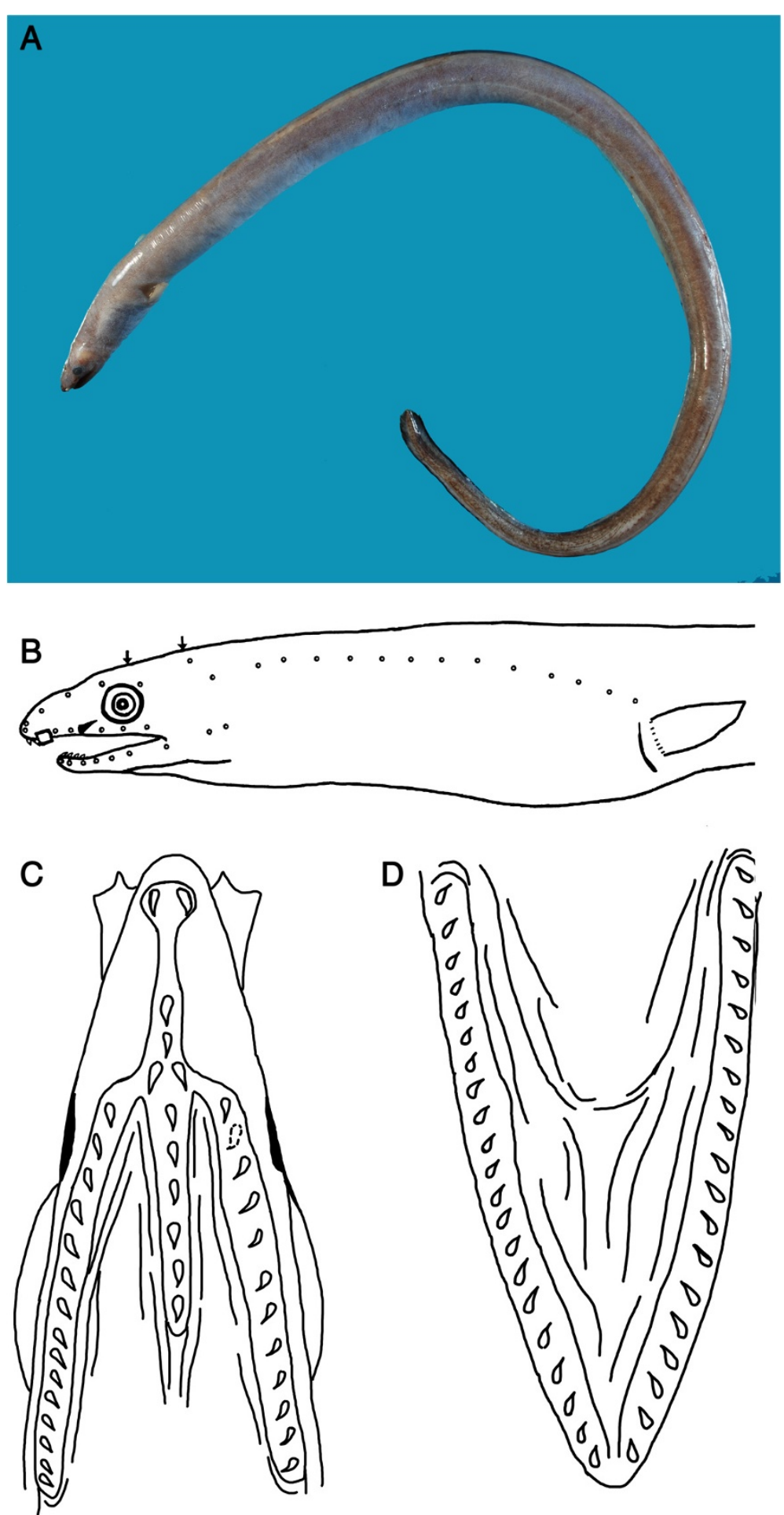

Figure 8 Neenchelys pelagica sp. nov. (A) Holotype, NMMB-P15556, 392 mm TL, Tungkang, Taiwan, preserved condition. (B) Lateral view of head, with arrows indicating the frontal pore (left) and median supratemporal pore (right). (C) Upper jaw teeth. (D) Lower jaw teeth.

having a relatively rounded snout (vs. pointed), an MVF of 33-53-169 (vs. 19-50-140), and different body proportions (see Tables 1 and 3).
Neenchelys similis sp. nov.

Common name: Slender worm eel

(Figure 9A,B,C,D and Tables 3 and 4) 


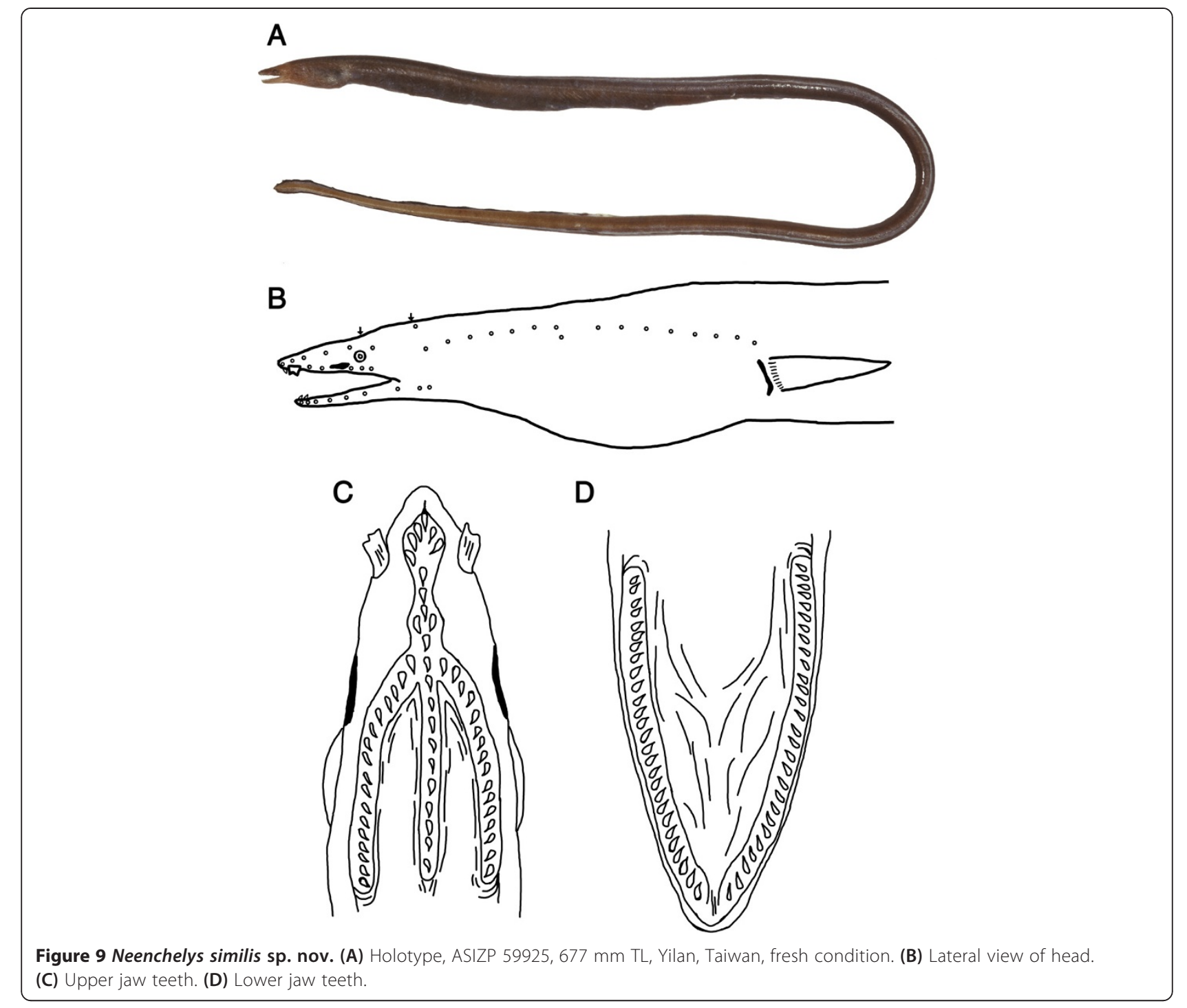

Synonymy: Neenchelys daedalus (non McCosker): McCosker 1982: 65 (non-types); Machida and Ohta 1993: 391 (description, Japan); Nakabo 2002: 217 (illustrated key, Japan); Chen 2007: 16 (description, Taiwan).

Holotype: ASIZP 59925, $677 \mathrm{~mm}$, female with immature eggs, Tashi Fishing Port, Ilan, NE Taiwan, bottom trawl, 20 March 1998, coll. M.-L. Chiou.

Paratype: NSMT-P105355 (580 mm), 3500' N, 138 40' E to $34^{\circ} 58.02^{\prime} \mathrm{N}, 138^{\circ} 40^{\prime} \mathrm{E}$, Suruga Bay, Japan, 1,376 to $1,450 \mathrm{~m}$, beam trawl, 13 November 1983, field no. ORIUT.KT.8318.11.0101. FRLM 38980 (756 mm), Nayaura, Minamiise, Mie, Japan, round haul net, 22 April 2011, coll. M. Okada. FRLM 42319 (714 mm), Nieura, Minamiise, Mie, Japan, round haul net, 6 March 2011, coll. M. Okada.

Non-types: AMS I.19707-017 (5, 172 to $187 \mathrm{~mm})$, CAS 50709 (2, 187 to $225 \mathrm{~mm}$ ), CAS 50710 (190 mm), ANSP 149295 (2, 175 to $185 \mathrm{~mm}$ ), Manus Island, Papua New
Guinea, $04^{\circ} 15^{\prime} \mathrm{S}, 145^{\circ} 11^{\prime} \mathrm{E}, 6$-ft IKMT, 0 to $125 \mathrm{~m}$, over a bottom at 750+ m, FRV TAGULA, 22 October 1969, coll. J. E. Paxton; SIO 77 to 171 (144 mm), Banda Sea, $105 \mathrm{~km} \mathrm{SW}$ of Buru I., $04^{\circ} 30.5^{\prime} \mathrm{S}, 125^{\circ} 34.6^{\prime} \mathrm{E}, 0$ to $1500 \mathrm{~m}$ over a 3,600-m bottom, 26 August 1976, coll. J. Coatsworth.

Etymology: From the Latin similis, like, in reference to its similarity to its congener, $N$. daedalus.

Diagnosis: A species of Neenchelys distinguished by the combination of the following characters: body extremely elongate and slightly compressed, its depth 2.6 to 3.0 times in HL, 43 to 48 in TL; dorsal fin origin at anterior $1 / 3$ of trunk, 1.0 to 1.3 times in $\mathrm{HL}$ behind gill opening; predorsal length 6.8 to 7.7 in TL; head relatively short, 15.1 to 16.3 in TL; trunk 4.6 to 4.8 in TL; tail extremely long, 1.4 in TL; pectoral fin well developed, longer than snout. Total vertebrae 260 to 265; MVF 34-68-262. Cephalic lateral line pores 15 to 16 ; predorsal pores 35 to 37 ; preanal pores 70 or 71 . 
Description: Morphometric and meristic data are provided in Tables 3 and 4 . The following proportions are given for the holotype, followed by all types in parentheses. HL relatively short, 16.3 (15.1 to 16.3$)$ in TL; origin of dorsal fin about 1 to $1.3 \mathrm{HL}$ behind a vertical through gill opening, predorsal length 7.1 (6.8 to 7.7 ) in TL; trunk relatively short, its length 4.7 (4.6 to 4.8 ) in TL; anus at first $1 / 3$ to $1 / 4$ of body length; origin of anal fin immediately behind anus, preanal length 3.6 (3.5 to 3.7) in TL; tail relatively long, tail length 1.4 (1.4) in TL.

Body elongate, trunk somewhat cylindrical with gradually compressed tail posteriorly; body width at anus 4.0 (3.6 to 4.4) in HL; body depth relatively uniform, depth at anus 2.6 (2.6 to 3.0) in HL, tapering gradually to tip of tail; depth of head subequal to depth of body, 2.9 (2.9 to 3.4) in HL. Dorsal and anal fins low and fleshy, continuous with a small but distinct rayed caudal fin. Pectoral fin well developed, broad at base and pointed distally, its length 3.8 (3.8 to 4.2) in HL.

Head terete in profile; snout acute anteriorly and broad dorsally, snout length 5.5 (5.5 to 6.4) in HL; tip of snout projecting well beyond lower jaw; eye covered by a thick and semitransparent membrane; orbital width 18.9 (16.9 to 20.4) in HL; interorbital space relatively narrow, slightly elevated, its width 10.9 (10.9 to 15.9$)$ in HL; postorbital space relatively wide, its width 1.2 (1.2 to 1.3) in HL. Anterior nostril tubular, directed anteroventrally, its tube distinctly notched. Posterior nostril before lower margin of eye, opening directed ventrally, appearing in lateral aspect as a diagonal slit, the posterior end of which is highest. Behind, below, and paralleling the nostril with a groove that is longer than nasal slit. Lower jaw included, its tip reaching a line drawn between anterior margins of anterior nostrils. Angle of gape about one eye diameter behind a vertical through posterior margin of pigmented eyeball; rictus length 3.5 (3.0 to 3.7) in HL. Tongue well attached to mouth floor. Gill opening a narrow vertical slit situated at anteroventral corner of pectoral fin base, its height 12.2 (12.2 to 19.4) in $\mathrm{HL}$

Head pores small (Figure 9B), difficult to observe. Single median temporal and interorbital pores; supraorbital pores $1+4$; infraorbital pores $5+1$ ( 2 pores between anterior and posterior nostrils); mandibular pores 7 (6 or 7 ); preopercular pores 2; supratemporal pores 3. Lateral line incomplete, pores small and inconspicuous, extending posteriorly to about $2 / 3$ of TL. Cephalic lateral line pores 16 (15 to 16 ); predorsal pores 36 (35 to 37); preanal pores 71 (70 or 71$)$.

Teeth (Figure 9C,D) slender, pointed, tips directed backward, anterior few teeth in each series longest. Intermaxillary teeth 6 (5 to 6), well separated from those on vomer; vomerine teeth 15 (12 to 15), uniserial with a pair of side teeth between third and fourth teeth (between second and third in paratype), terminating posteriorly before end of maxillary tooth row; maxillary with 16 or 17 (16 to 18) small teeth, uniserial, terminating posterior to gape; dentary with 27 or 28 (26 to 28 ) small teeth, uniserial, terminating opposite end of maxillary tooth row (based on holotype and NSMT-P105355).

Coloration: In preservative uniform yellowish brown, with posterior portion of dorsal and anal fins edged in black.

Distribution and habitat: Known from Japan, Taiwan, New Guinea, and the Banda Sea. It was collected in midwater at depths of 0 to $1,500 \mathrm{~m}$ over bottom depths to 3,600 m.

Remarks: McCosker (1982) included this species under his newly described $N$. daedalus, noting the difference in vertebral number and excluding them from the type series. Specimens were subsequently reported from Japan (Machida and Ohta 1993) and Taiwan (Chen 2007); we describe them as this new species. It is notable that the non-types have a wider range of total vertebrae than those of type series ( 251 to 274 vs. 260 to 265 ). It may provide a broader range of the total vertebrae when more specimens are available.

After this paper was accepted, before going in press, Mr. Y. Hibino (personal communication, 23 June 2013) of Mie University kindly informed the senior author the presence of two specimens of $N$. similis sp. nov. collected from Mie, Japan. The senior author examined the photos and the morphological and meristic data of these two specimens which agree well with those of type series. These two specimens were recognized as additional paratypes of $N$. similis sp. nov., and these data were combined into the text and tables.

\section{A key to species of Neenchelys}

1A. Origin of dorsal fin above or behind level of anal opening.................................... cheni (Indo-west Pacific)

1B. Origin of dorsal fin well before anal opening...............2

2A. Pectoral fin minute, a tiny flap, shorter than

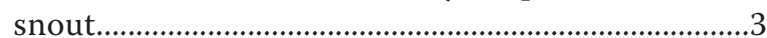

2B. Pectoral fin well developed, longer than snout............5

3A. Head short, 13.0 to 15.6 times in TL; total vertebrae 172 to $184 \ldots . . . . . N$. mccoskeri (West Pacific: Japan and Taiwan)

3B. Head long, 8.8 to 9.9 times in TL; total vertebrae 138 to 151.

4A. Total vertebrae 151

4B. Total vertebrae 138 to 148 ...N. parvipectoralis (South China Sea)

5A. Body and tail extremely elongate, body depth behind gill openings 54 to 55 in TL; total vertebrae 225 to 265.

5B. Body and tail moderately robust, body depth behind gill openings $<40$ in TL; total vertebrae $<170 \ldots \ldots . . . . . . . . .7$ 
6A. Lower jaw with five mandibular pores; total vertebrae 225 to 235 N. daedalus (Papua New Guinea)

6B. Lower jaw with six or seven mandibular pores; total vertebrae 251 to 274 . .....N. similis sp. nov. (West Pacific: Japan and Taiwan)

7A. Dorsal fin origin at anterior $1 / 5$ of trunk, 0.4 to $0.5 \mathrm{HL}$ behind gill opening; total vertebrae 135 to 148. ..N. buitendijki (Indo-west Pacific)

7B. Dorsal fin origin at midpoint of trunk, 1.0 to 1.4 HL behind gill opening; total vertebrae 169 or more.

8A. Total vertebrae 169; mandibular pores 7; gill opening height $6.6 \%$ to $7.9 \%$ of $\mathrm{HL}$

..N. pelagica sp. nov. (South China Sea: Taiwan)

8B. Total vertebrae 177 to 186 ; mandibular pores 6; gill opening height $8.8 \%$ to $12.6 \%$ of HL.

............ diaphora sp. nov. (South China Sea: Taiwan)

\section{Results and discussion}

Smith and Böhlke (1983: 83) discussed the problem of defining genera among the myrophine eels in which the posterior nostril opening is above the lip. Two of the characters they emphasized, the degree of development of the pectoral fin and the position of the dorsal fin origin, now appear less significant. The pectoral fin of the species treated here varied from well developed to rudimentary, and the dorsal origin varied from shortly behind the gill opening to behind the anus. Of the five groups mentioned by Smith and Böhlke (1983), Benthenchelys is the most distinct and can largely be eliminated from the discussion. It is small, short-headed, and large-eyed and possesses osteological characters that merit its recognition as a tribal sister group to the Myrophini (McCosker 1977). They also separated $N$. daedalus from other species known at the time ( $N$. microtretus, $N$. buitendijki, and $N$. parvipectoralis) by its pelagic habits and dorsal fin origin, but as we have shown, this species conforms well with the others. That leaves only Neenchelys (as treated here) and Pseudomyrophis (which is known from the Atlantic and eastern Pacific).

A monotypic myrophine genus, Pylorobranchus (type species Pylorobranchus hoi McCosker, Chen and Lin, in McCosker et al. 2012), was recently described by McCosker et al. (2012) based on a series of large deepwater eels captured off eastern Taiwan. It is similar to species of Neenchelys and Pseudomyrophis in having the posterior nostril above the upper lip, but differs in being much more robust, having elongate jaws that do not completely close, and in possessing a third preopercular pore.

Eels of the genus Neenchelys appear to represent a closely related group, characterized by the position and form of the posterior nostril. It is a somewhat elongate slit on the side of the head above the lip, oriented obliquely in an anteroventral to posterodorsal direction, and is completely exposed (i.e., without a flap). Other characters include the terete form of the head and the presence of at least a rudimentary pectoral fin. A few other Indo-west Pacific myrophines, e.g., species of Skythrenchelys and Muraenichthys, also have the posterior nostril above the lip, but they greatly differ in appearance, with shorter heads and blunter snouts (Castle and McCosker 1999). Their posterior nostril is smaller than that of Neenchelys and is preceded by a dermal flap. Moreover, they lack all traces of a pectoral fin.

Species of Neenchelys most closely resemble those of Pseudomyrophis, which are found in the Atlantic and eastern Pacific. They share numerous osteological characters and have a similar posterior nostril condition. Prior to subsequent descriptions of several species of both genera, Nelson (1966) examined the osteology of $N$. buitendijki and commented upon Wade's description of Pseudomyrophis micropinna Wade 1946, the type of his new genus. Nelson stated that 'there is no character significant enough to maintain Pseudomyrophis as a genus distinct from Neenchelys. Pseudomyrophis nimius Böhlke 1960, on the other hand, seems distinctive enough to be placed in a genus of its own.' McCosker (1977: 60-61) was later able to examine the osteology of P. micropinna and P. nimius and found them to be congeners. He separated species of Neenchelys from those of Pseudomyrophis on the basis of snout shapes (conical vs. broad), third preopercular pore (absent vs. present), and subopercle condition (small and subrectangular vs. produced posteriorly along the ventral and posterior margins of the opercle).

The larvae provide further evidence for distinguishing between Neenchelys and Pseudomyrophis. Castle (1980) described larvae of two species of Neenchelys from the western Pacific as being characterized by a short gut, relatively deep body, four gut swellings, and a distinctive series of lateral pigment spots. There are three horizontally elongate streaks of melanophores along the midline at about midbody, with an additional group of melanophores just above and below the posterior lateral streak (Figure 10A). These larvae are quite distinct from those described for Pseudomyrophis (Blache 1977: 98-204; Leiby 1989: 774-786), which are more elongate, with more gut swellings and more lateral melanophores (Figure 10B). Significantly, larvae of the Neenchelys type have never been found in the Atlantic, where adults of Pseudomyrophis occur.

Species of Neenchelys are characterized by variations in several characters. Neenchelys daedalus and N. similis sp. nov. have extremely elongate bodies, with a maximum depth of 43 to 52 in TL. Neenchelys mccoskeri is moderately elongate, with a maximum body depth of 31 to 57 in TL. The remaining species are more robust, 

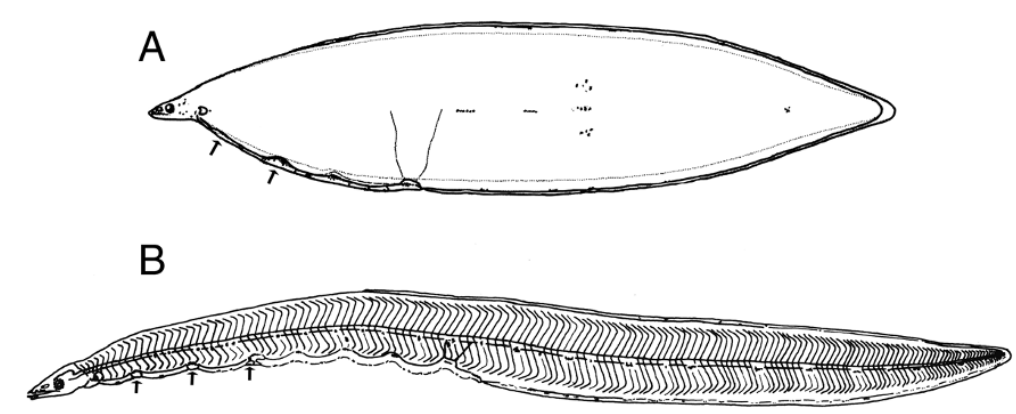

Figure 10 Neenchelys microtretus (A), leptocephlaus, 75 mm TL. Modified from Castle, 1980, Figure one A. Pseudomyrophis sp. (B), euryodontic stage, FDNR 16560L, $45 \mathrm{~mm}$ TL. Modified from Leiby, 1989, Figure seven hundred and seventy four. Arrows indicate the liver lobes. Not to scale.

with body depths of 19 to 40 in TL. Neenchelys diaphora sp. nov., $N$. cheni, N. mccoskeri, and $N$. pelagica sp. nov. are the largest of the species, reaching about $400 \mathrm{~mm}$ $\mathrm{TL}$ or more. The remaining species grow to about $300 \mathrm{~mm}$.

The pectoral fin varies greatly in size. Neenchelys buitendijki, $N$. daedalus, $N$. diaphora sp. nov., $N$. pelagica sp. nov., and $N$. similis sp. nov. have a well-developed pectoral fin, $20 \%$ or more of the HL. Neenchelys cheni has a smaller but still prominent pectoral fin, at $10.3 \%$ to $16.4 \%$ of HL. In N. mccoskeri, N. microtretus, and $N$. parvipectoralis, the pectoral fin is reduced to little more than a rudiment, of no more than $1.2 \%$ to $4.2 \%$ of the HL (data only from N. mccoskeri and N. parvipectoralis, but presumed for $N$. microtretus). The position of the dorsal fin origin also greatly varies among species. In $N$. cheni, it is far posterior, over or behind the anus. In $N$. diaphora sp. nov., $N$. mccoskeri, and $N$. pelagica sp. nov., the dorsal origin is at about midtrunk. The dorsal origin of the remaining species is at the anterior $1 / 5$ to $2 / 5$ of the trunk.

Sensory pores on the head and body show some variation among species. The infraorbital series contains $5+1$ pores in all species, except for $N$. cheni and $N$. mccoskeri which occasionally have $5+2$. Supraorbital series contains $1+4$ pores in all species, except for $N$. cheni which occasionally has $1+5$. Mandibular pores number 5 or 6 (mainly 5) in N. cheni, N. daedalus, and N. microtretus; 6 in $N$. diaphora sp. nov.; 6 or 7 in $N$. parvipectoralis; and 7 in $N$. buitendijki, N. mccoskeri (6 or 7, mainly 7), $N$. pelagica sp. nov., and $N$. similis sp. nov. Predorsal lateral line pores vary among species, reflecting a variation in the position of the dorsal fin origin. The number of preanal pores can also be used to distinguish some of the species.

Finally, species differ in their habitat. Neenchelys daedalus, $N$. pelagica sp. nov., and $N$. similis sp. nov. are the only members of the Ophichthidae other than Benthenchelys that live in midwater as adults. There is some evidence that $N$. cheni may live pelagically as well, at least in part of its life, but the remaining species are all benthic. It is possible that pelagic-living species tend to have a well-developed pectoral fin, whereas bottom living species have strongly reduced pectoral fins. Some members with a well-developed pectoral fin might be benthopelagic, living and/or feeding near the bottom.

\section{Conclusions}

The knowledge of the Indo-west Pacific worm eel genus Neenchelys has been greatly improved. Totally, nine species are recognized currently, including three newly described species. Data are provided on the basis of type series together with specimens newly collected form a broader range. New diagnostic characters are employed for recognizing the congeners and to establish the new species. A key to all known species of Neenchelys is provided for the first time. This study would provide a good example in terms of understanding the world eel diversity and their geographic distributions. Intensive collections are needed for further understanding of the biology and ecology of this group.

\section{Competing interests}

The authors declare that they have no competing interests.

\section{Authors' contributions}

$\mathrm{H}-\mathrm{CH}$ collected most specimens for this study, conducted the eel study in Taiwan, gathered all information, and prepared the early draft. $\mathrm{H}-\mathrm{CH}$, JEM, and DGS conceived the study, each examined at least part of the type series of those nominal species, provided data, discussed the taxonomic problems, and completed the manuscript. All authors read and approve the final manuscript.

\section{Acknowledgements}

We thank H. Endo (BSKU), G. Shinohara (NSMT-P), P.-L. Lin (ASIZP), S.-Y. Wang (NMMB-P), D. Catania and M. Hoang (CAS), and H.-L. Wu and X.-D. Liu (Shanghai Ocean University) for curatorial assistance and W.-D. Chen for preparing the line drawings. Special thanks go to Y. Hibino (FRLM) for providing the figures and detailed data of two paratypes of $\mathrm{N}$. similis and $\mathrm{F}$. Tashiro (HUMZ) for useful comments. We thank three anonymous reviewers for critically reviewing the manuscript and useful suggestions. This study was supported by grants from the National Science Council (NSC102-2621-B-291002) and National Museum of Marine Biology and Aquarium, Taiwan (NMMBA 101200254). 


\section{Author details}

${ }^{1}$ National Museum of Marine Biology and Aquarium and Institute of Marine Biodiversity and Evolutionary Biology, National Dong Hwa University, Pingtung 944, Taiwan. ${ }^{2}$ California Academy of Sciences, 55 Music Concourse Drive, San Francisco, CA 94118, USA. ${ }^{3}$ Museum Support Center, National Museum of Natural History, Smithsonian Institution, 4210 Silver Hill Road, Suitland, MD 20746, USA.

Received: 21 November 2012 Accepted: 26 June 2013

Published: 12 December 2013

\section{References}

Bamber RC (1915) Reports on the marine biology of the Sudanese Red Sea, from collections made by Cyril Crossland, MA, B. Sc., FZS-XXII. The fishes. J Linn Soc Lond Zool 31:477-485

Blache J (1977) Leptocéphales des poissons anguilliformes dans la zone sud du Golfe de Guinée. Faune Trop 20:1-381

Böhlke JE (1960) A new ophichthid eel of the genus Pseudomyrophis from the Gulf of Mexico. Notulae Naturae 329:1-8

Böhlke EB (1989) Methods and terminology. In: Böhlke EB (ed) Fishes of the western North Atlantic. Part 9, vol. 1: Orders Anguilliformes and Saccopharyngiformes. Yale Univ Press, Boston, pp 1-7

Castle PHJ (1972) The eel genus Benthenchelys (fam. Ophichthidae) in the Indo-Pacific. Dana Rep 82:1-32

Castle PHJ (1980) Larvae of the ophichthid eel genus Neenchelys in the Indo-Pacific. Pac Sci 34:165-171

Castle PHJ, McCosker JE (1999) A new genus and two new species of myrophine worm-eels, with comments on Muraenichthys and Scolecenchelys (Anguilliformes: Ophicthidae). Rec Aust Mus 51:113-122

Chen WL (2007) Preliminary studies on the taxonomy of snake-eels (Ophichthidae, Anguilliformes) off eastern Taiwan. National Ocean University, Keelung, Taiwan, Master's thesis

Chen JTF, Weng HTC (1967) A review of the apodal fishes of Taiwan. Biol Bull Tunghai Univ Ichthyol Ser 6:1-86

Chu YT, Wu HL, Jin XB (1981) Four new species of the families Ophichthyidae and Neenchelidae. J Fish China 5:1-27

Fowler HW (1934) Descriptions of new fishes obtained 1907 to 1910, chiefly in the Philippine Islands and adjacent seas. Proc Acad Nat Sci Phila 85:233-367

Fricke R, Eschmeyer WN (2013) Guide to fish collections. Available at http:// research.calacademy.org/research/ichthyology/catalog/collections.asp. Accessed Mar. 2013

Hibino Y, Ho H-C, Kimura S (2012) A new worm eel Neenchelys mccoskeri (Anguilliformes: Ophichthidae) from Taiwan and Japan. Ichthyol Res 59:342-346

Ho H-C, Smith DG, Wang S-I, Shao K-T, Ju Y-M, Chang C-W (2010) Specimen catalog of Pisces collection of National Museum of Marine Biology and Aquarium transferred from Tinghi University and Aquarium. (II) Order Anguilliformes. Platax 7:13-34

Ho H-C, Teoh HW, Chong VC (2012) Notes on the snake eel Neenchelys buitendijki (Ophichthidae: Myrophinae), a first record from Malaysia. Sci Malaysiana 41:949-952

Leiby MM (1984) Ophichthidae. Development and relationships. In: Moser HG, Richards WJ (ed) Ontogeny and systematics of fishes. Special publication American Society of Ichthyologists and Herpetologists. 1:102-108

Leiby MM (1989) Family Ophichthidae: Leptocephali. In: Böhlke EB (ed) Fishes of the western North Atlantic. Part 9, vol. 2: Leptocephali. Yale Univ Press, Boston, pp 764-897

Machida Y, Ohta S (1993) New record for Neenchelys daedalus (Ophichthidae) from Japan. Jpn J Ichthyol 39:391-394

McCosker JE (1977) The osteology, classification, and relationships of the eel family Ophichthidae. Proc CA Acad Sci Ser 4(41):1-123

McCosker JE (1982) A new genus and two new species of remarkable Pacific worm eels (Ophichthidae, subfamily Myrophinae). Proc CA Acad Sci Ser 4 (43):59-66

McCosker JE (2014) Family Ophichthidae (snake eels, sand eels, and worm eels). In: Heemstra P, Holleman W (ed) Coastal fishes of the Western Indian Ocean South African Institute for Aquatic Biodiversity, Grahamstown. in press

McCosker JE, Chen YY (2000) A new species of deepwater snake-eel, Ophichthus aphotistos, with comments on Neenchelys retropinna (Anguilliformes: Ophichthidae) from Taiwan. Ichthyol Res 47:353-357
McCosker JE, Böhlke EB, Böhlke JE (1989) Family Ophichthidae. In: Böhlke EB (ed) Fishes of the western North Atlantic. Part 9, vol. 1: Orders Anguilliformes and Saccopharyngiformes. Yale Univ Press, Boston, pp 254-412

McCosker JE, Loh K-H, Lin J, Chen H-M (2012) Pylorobranchus hoi, a new genus and species of myrophine worm eel from Taiwan (Anguilliformes: Ophichthidae). Zool Stud 51:1188-1194

Mohamed KH (1958) On the occurrence of the eel Neenchelys buitendijki Weber and de Beaufort in Indian waters. J Bombay Nat His Soc 55:511-517

Nakabo T (2002) Fishes of Japan with pictorial keys to the species, English edition, vol 1. Tokai Univ Press, Tokyo

Nelson GJ (1966) Osteology and relationships of the eel, Neenchelys buitendijki. Copeia 1966:321-324

Nelson GJ (1967) Notes on the systematic status of the eels Neenchelys and Myroconger. Pac Sci 21:562-563

Paxton JR, Hoese DF, Allen GR, Hanley JE (1989) Pisces. Petromyzontidae to Carangidae. Zoological Catalogue of Australia. Vol. 7. Australian Government Publishing Service, Canberra, Australia

Smith DG, Böhlke JE (1983) Neenchelys retropinna: a new worm eel (Pisces: Ophichthidae) from the Indian Ocean. Proc Acad Nat Sci Phila 135:80-84

Smith DG, McCosker JE (1999) Family Ophichthidae. In: Carpenter KE, Niem VH (ed) FAO species identification guide for fishery purposes. The living marine resources of the western central Pacific. Vol. 3. Batoid fishes, chimaeras and bony fishes part 1 (Elopidae to Linophrynidae). Food and Agricultural Organization, Rome, pp 1662-1669

Wade CB (1946) Two new genera and five new species of apodal fishes from the eastern Pacific. Allan Hancock Pac Exped 9:181-213

Weber M, de Beaufort LF (1916) The fishes of the Indo-Australian Archipelago. III. Ostariophysi: II Cyprinoidea, Apodes, Synbranchi. EJ Brill, Leiden, the Netherlands

doi:10.1186/1810-522X-52-58

Cite this article as: Ho et al:: Revision of the worm eel genus Neenchelys (Ophichthidae: Myrophinae), with descriptions of three new species from the western Pacific Ocean. Zoological Studies 2013 52:58.

\section{Submit your manuscript to a SpringerOpen ${ }^{\odot}$ journal and benefit from:}

- Convenient online submission

- Rigorous peer review

- Immediate publication on acceptance

- Open access: articles freely available online

- High visibility within the field

- Retaining the copyright to your article

Submit your next manuscript at $>$ springeropen.com 